\title{
Role of the Forebrain Commissures in Bihemispheric Mnemonic Integration in Macaques
}

\author{
Jeffrey D. Lewine, Robert W. Doty, Robert S. Astur, and Sherri L. Provencal \\ Department of Physiology, University of Rochester School of Medicine and Dentistry, Rochester, New York 14642
}

\begin{abstract}
A serial probe recognition task was used to examine the interhemispheric exchange of visual data in macaques. Each block of trials began with the memorization of one to six visual target images. The monkeys then had to determine, in tests that followed immediately, whether probe images were or were not members of the learned target set. Previous work with both humans and macaques has shown that the time required for the evaluation of probes generally increases, while response accuracy decreases, as a function of the number of targets, the "memory load." By testing animals with bisected optic chiasm, it was possible to direct visual information to only one hemisphere at a time, simply by occluding the opposite eye. In this fashion, the quality of intrahemispheric evaluations (in which a monocular probe was a match for a target previously viewed through the same eye) was compared with that of interhemispheric evaluations (in which a probe was a match for a target previously designated through the opposite eye). A key question was whether division of the target list between the hemispheres modified the relationships between reaction time, response accuracy, and memory load. Provided that either the anterior commissure or the splenium of the corpus callosum was intact, interhemispheric processing was only subtly less efficient than intrahemispheric processing. The ability to perform interhemispheric evaluations was selectively and completely disrupted if all forebrain commissural fibers were transected. In this latter split-brain condition, the time required for probe evaluations was, as expected, determined solely by the number of target items memorized by the probed hemisphere. Accuracy, however, was always a function of the total memory load, regardless of the distribution of targets between the hemispheres. This implies, first, that accuracy and latency do not reflect identical mnemonic factors, as frequently held, and second, that in mnemonic processing, the two hemispheres draw upon a unified, shared resource, probably allocated by the intact brainstem.
\end{abstract}

[Key words: corpus callosum, anterior commissure, memory, brainstem, macaques, reaction time, vision]

\footnotetext{
Received June 24, 1993; accepted Sept. 14, 1993.

This work was supported by Javits Award NS20052 to R.W.D., U.S. Public Health Service Predoctoral Fellowship 5-F31 -MH09117 to J.D.L., and Girant T89. 01245-013 to J.D.L. from the McDonnell-Pew Program in Cognitive Neuroscience. We are grateful to $M$. DeRycke for his assistance in training and testing some of the animals.

Correspondence should be addressed to Dr. Jeffrey David Lewine, Department of Radiology (114M), Veterans Administration Medical Center, 2100 Ridgecrest Drive, SE, Albuquerque, NM 87108.

Copyright (C) 1994 Society for Neuroscience $0270-6474 / 94 / 142515-16 \$ 05.00 / 0$
}

There is now abundant evidence from hemispherectomy or total section of the forebrain commissures that each cerebral hemisphere is capable, as anatomy would suggest, of supporting a full range of human consciousness and intellectual experience (e.g., Griffith and Davidson, 1966; Gott, 1973; Austin et al., 1974; Smith, 1974; Schepelmann et al., 1976; Sperry et al., 1979; Ogden, 1989; Patterson et al., 1989). A profound and commonly ignored question thus arises as to how, in neurologically intact persons, a unity of mind and action is achieved from two potentially disparate and independent hemispheres. It is obvious from observations of humans and animals that the forebrain commissures (i.e., the corpus callosum and anterior commissure) somehow provide the essential mechanism in forging this unity, yet the manner in which this is achieved remains obscure.

Since, in both human and macaque, elimination of the forebrain commissures precludes exchange of most information between the hemispheres, the obverse question is also of interest: could, or do, cortically disconnected hemispheres each operate in isolation and thereby double the overall processing capacity of the brain? This issue has been addressed from time to time. For instance, Luck et al. (1989) found that disconnected cerebral hemispheres can each support an independent attentional focus capable of operating in parallel with that of the other hemisphere, a situation not found for the intact brain. In contrast, the extent to which commissurotomy can lead to a doubling of mnemonic (as distinct from attentional) capacity is unclear. Some studies suggest that commissurotomy allows each hemisphere to act as an independent mnemonic processing system (e.g., Gazzaniga and Young, 1967; Holtzman and Gazzaniga, 1985), whereas others imply that even such disconnected hemispheres must still share and compete for limited processing resources (Holtzman and Gazzaniga, 1982).

Critical evaluation of the memory experiments remains difficult, because the methods employed fail to separate mnemonic processing factors definitively from perceptual and attentive factors. In each of these studies, the hemispheres were simultaneously presented with different to-be-remembered visual information. For example, at each instant in time in the study of Gazzaniga and Young (1967), each eye of their monkey subjects viewed different visuospatial cues. Perhaps the apparent ability of animals with transected commissures and optic chiasm to remember more of the presented information than intact controls really reflected an inability on the part of the controls to attend and perceive simultaneously bilaterally disparate visual information.

To clarify the mechanisms of bihemispheric mnemonic integration and independence, the present studies utilized a probe recognition task that is explicitly designed to isolate mnemonic 
Figure 1. The serial probe recognition task. Presentation of a target set of one to six images is followed by pseudorandom presentation of a sequence of test probes. Subjects must determine as rapidly as possible whether a probe image is positive, that is, a member of the target set, or negative, not a member of the target set. Note the left-right symmetry of the images, which forestalls noncomparable views that might otherwise be acquired by each eye after transection of the optic chiasm.

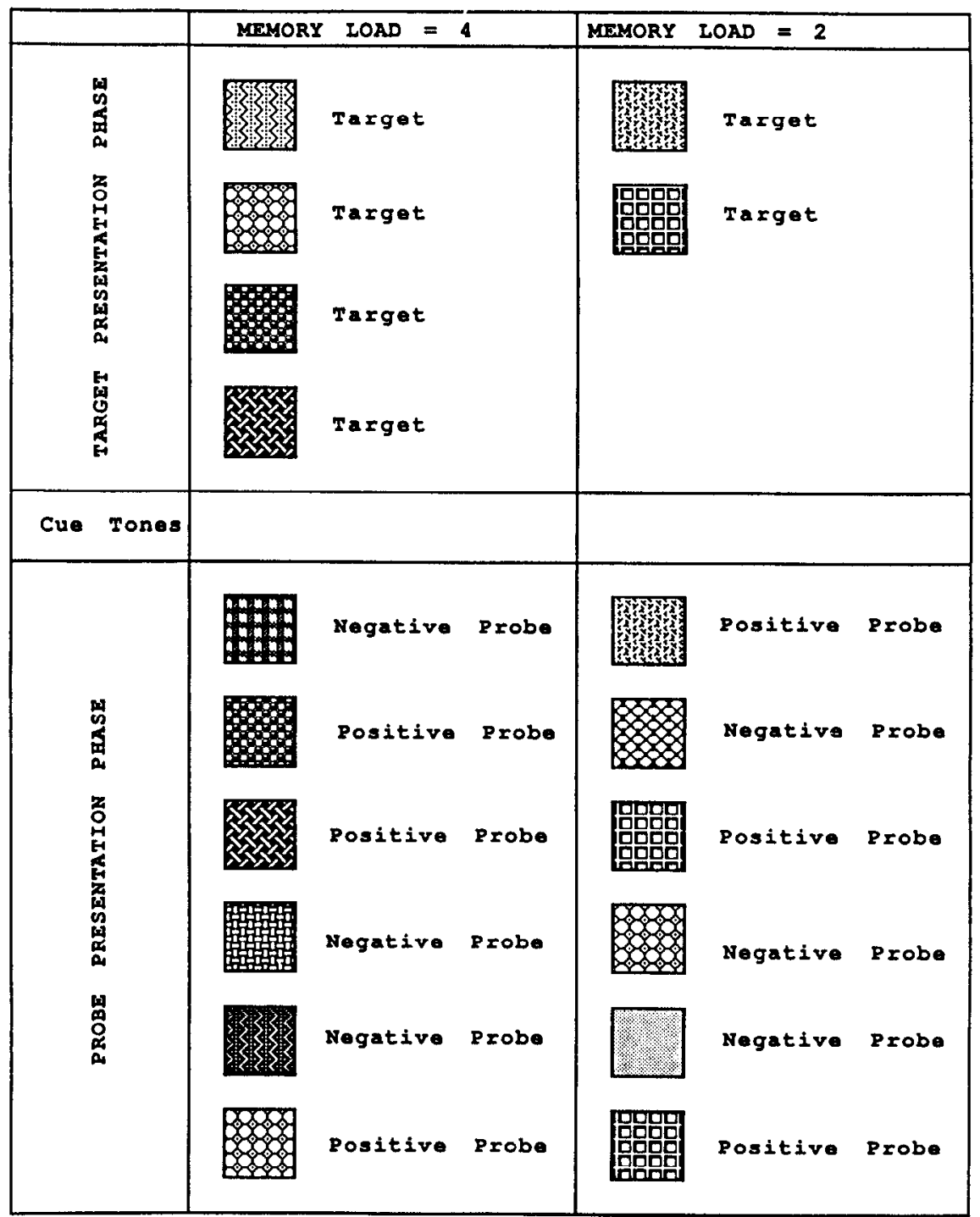

from other processing factors (Sternberg, 1966, 1969). As illustrated in Figure 1, in each test block of this paradigm subjects must classify probe stimuli as positive versus negative according to the stimuli's presence versus absence from a prememorized set of target stimuli. On each probe trial only a single stimulus need be attended and perceived, only a single positive/negative response decision is required, and only a single motor response is generated. Hence, the amount of time required for the execution of these nonmnemonic processes is independent of the memory load, that is, the number of target items being remembered. Yet, for target sets of up to six items, the average latency of behavioral response increases as a nearly linear function of memory load (Sternberg, 1966, 1969, 1975). This indicates that there is at least one load-dependent processing stage, with the rate of retrieval of short-term mnemonic information being behaviorally specified by the slope of the function relating reaction time to memory load (shallow slopes imply efficient processing - little processing time added per target item; steep slopes imply inefficient retrieval). Hence, if intra- and interhemispheric conditions are found to differ in the slope of reaction time functions, there is a difference in the mnemonic retrieval process per se. In contrast, differences in the intercepts of func- tions would imply differences in nonmnemonic perceptual and response processes (Fig. 2).

The remarkable similarity between human and macaque visual mnemonic abilities (Ringo and Doty, 1985; Ringo et al., 1986; Doty et al., 1988a; Gower, 1990), and the ability to restrict, in series, the availability of selected commissural pathways, makes macaques ideal subjects for studies of interhemispheric mnemonic processing (Doty et al., 1988b). Monkeys can perform Sternberg's probe recognition task as accurately as human subjects (Sands and Wright, 1982; Lewine, 1989) while demonstrating significantly more shallow reaction time functions, a result implying that macaques probably possess the more efficient short-term mnemonic retrieval mechanisms (Lewine et al., 1987; Lewine, 1989).

The key to examining interhemispheric abilities in monkeys is restriction of the output of each eye to only the ipsilateral hemisphere via surgical transection of the optic chiasm. Intraand interhemispheric abilities can then be compared by presenting each target to only one eye, and then requiring the same or contralateral eye to make evaluations of positive probe (target) items. Using this strategy, intra- and interhemispheric processing was qualitatively and quantitatively evaluated following 
Table 1. Testing and surgical sequence

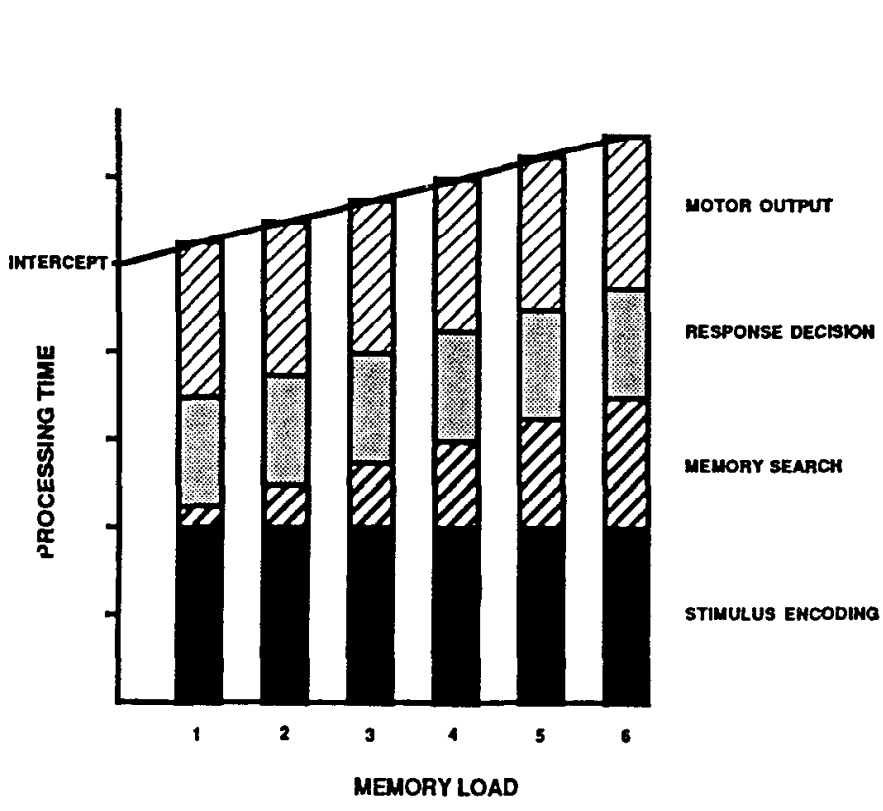

Figure 2. A stage analysis of reaction time. Probe evaluation is conceived to be achieved via execution of a sequence of processing stages, including a stimulus-encoding (SE) stage, a memory-search (MS) (probetarget comparison) stage, a binary $( \pm$ ) response decision (RD) stage, and a motor response generation (MO) stage. Overall reaction time reflects the sum of the times required for execution of each stage. If conditions (e.g., intra- vs interhemispheric trials) vary in the intercepts of functions, this implies differences in encoding, decision, and/or response stages. Differences in slopes imply differences in the rate of mnemonic retrieval per se.

partial and complete commissurotomy. Overall, there were three major issues addressed in this study.

(1) Interhemispheric processing. To what extent is interhemispheric processing as efficient as intrahemispheric processing for animals with partial commissurotomy? Is the bihemispheric mnemonic integration achieved through the anterior commissure equivalent to that achieved through the splenium?

(2) Hemispheric asymmetries. Is one or the other hemisphere inherently superior in its intrahemispheric performance, or in its role as the initial receiver of information required for subsequent interhemispheric evaluation?

(3) Bihemispheric integration. To what extent can partially or completely disconnected hemispheres function as independent mnemonic systems?

\section{Materials and Methods}

Subjects and surgical preparation. Six male Macaca nemestrina served as subjects, each for a period of $2-4.5$ years, as they grew from juveniles to young adults (ca. $5-15 \mathrm{~kg}$ ). The animals were housed under veterinary supervision, and each was given free access to food while in its home cage. Fluid intake was generally limited to that received as a reward during behavioral testing. Reward parameters were adjusted to ensure that each animal received a generous daily allotment of fluid in excess of $80 \mathrm{ml} / \mathrm{kg}$, and this was also supplied ad libitum on days without training or testing.

Table 1 provides details of the sequence of surgical and testing procedures for each animal. Two of the six animals, Lan-I and Walt-I, were tested only in the intact state. After extensive testing while intact, three animals (Art-AC, Spa-AC, and Buck-SP) underwent surgical bisection of the optic chiasm via the ventral transphenoidal approach devised by

\begin{tabular}{llllll} 
& & $\begin{array}{l}\text { OX } \\
\text { tran- } \\
\text { sected, } \\
\text { AC, CC } \\
\text { intact }\end{array}$ & $\begin{array}{l}\text { AC \& } \\
\text { ant. CC } \\
\text { transected } \\
\text { splenium } \\
\text { intact }\end{array}$ & $\begin{array}{l}\text { Callo- } \\
\text { sotomy, } \\
\text { AC intact }\end{array}$ & $\begin{array}{l}\text { Full } \\
\text { split }\end{array}$ \\
\hline Animal & Intact & - & - & - \\
Walt-I & $\mathrm{X}$ & - & - & - & - \\
Lan-I & $\mathrm{X}$ & - & - & $\mathrm{X}$ & $\mathrm{X}$ \\
Art-AC & $\mathrm{X}$ & $\mathrm{X}$ & - & $\mathrm{X}$ & $\mathrm{X}$ \\
Spa-AC & $\mathrm{X}$ & $\mathrm{X}$ & - & $\mathrm{X}$ \\
Buck-SP & $\mathrm{X}$ & $\mathrm{X}$ & $\mathrm{X}$ & - & $\mathrm{X}$ \\
Mer-SP & - & - & $\mathrm{X}(\mathrm{ox})^{a}$ & - & $\mathrm{X}$
\end{tabular}

$\mathrm{X}$ indicates that animal was tested following the listed surgical intervention. $\mathrm{OX}$, optic chiasm; AC, anterior commissure; ant. CC, anterior two-thirds of the corpus callosum.

${ }^{a}$ The optic chiasm was transected during the listed surgical procedure.

Downer (1959). One animal (Mer-SP) did not receive extensive training or testing until after initial surgery, which involved transection of the chiasm, anterior commissure, and all but the posterior $5 \mathrm{~mm}$ of the splenium of the corpus callosum via a dorsal approach. The details of these surgical procedures followed those set forth by Trevarthen (1972). Strict aseptic precaution was taken in the dorsal invasion, and to every degree possible in the transphenoidal approach.

Following testing in the chiasm-transected state, animals Art-AC and Spa-AC underwent callosotomy, leaving the anterior commissure as the only remaining forebrain commissural pathway (the hippocampal commissure was transected along with the callosum). After testing in the chiasm-transected state, the anterior commissure and anterior callosum were transected in Buck-SP, to leave only the posterior $5 \mathrm{~mm}$ of the splenium of the callosum intact. The commissural status of Buck-SP at this point was thereby equivalent to that of Mer-SP following his initial surgery.

After determination of performance with only splenium or anterior commissure intact, these structures were then also transected to leave animals Art-AC, Spa-AC, Buck-SP, and Mer-SP as fully split-brain animals. This second surgical entry into the midline was, of course, complicated by adhesions and vascular proliferation consequent to the first procedure. It is likely that most of the extracallosal damage subsequently noted post-mortem (see Table 7) is attributable to this second intervention.

Upon termination of a final round of formal testing in this study (and some additional testing in a separate study), each split-brain animal was deeply anesthetized and the brain was removed after intracardiac perfusion with saline followed by paraformaldehyde. Special care was employed in dissecting the region of the optic chiasm, and, in all instances, it was fully and unequivocally transected; its transected status was further confirmed histologically, and by the behavioral results in the splitbrain condition. After gross examination, frozen sections were cut and stained according to Weil and Nissl procedures.

Testing procedures. During testing, the monkeys squatted comfortably in a primate chair (see Glassman et al., 1969) facing three vertically aligned response panels onto which high-quality visual stimuli could be back projected. Each panel was $12 \times 7 \mathrm{~cm}, 3 \mathrm{~cm}$ separating the top and bottom of adjacent panels. The actual viewing distance depended upon the size and arm reach of each animal and ranged from 20 to $35 \mathrm{~cm}$. The chair was equipped with a front plate that restricted response to only one hand. Hand use was alternated from session to session.

Head movements were restricted via a snug-fitting snout plate equipped with solenoid-controlled shutters capable of selectively occluding the view of each eye (see Doty et al., 1988b). For an animal with bisected optic chiasm, this afforded the means of moment-to-moment control of which hemisphere received direct visual input (the viewing eye of a split-chiasm animal sending information to only the ipsilateral hemisphere).

At the start of each test set, a sequence of one, two, four, or six target images was projected, first on the middle response panel, and then again on the top panel, with only a single eye viewing each target. Monkeys self-initiated the presentation of each target item by pressing whichever panel was illuminated by a blue light. Following completed presentation 
of the target list, a sequence of tones and lights cued the beginning of the probe phase of testing.

Each probe trial began with presentation of a red light on the center panel. Subjects self-triggered actual presentation of a probe image on the top panel by maintaining a press on the center panel for $200 \mathrm{msec}$. By ensuring that subjects were "ready," attentive, and had assumed a highly reproducible hand and arm posture at the start of each trial, this overall procedure helped to minimize variability in the reaction time data.

If the probe was positive, that is, a member of the target set, the monkey had to press the top panel on which it was displayed in order to receive a juice reward. If the probe was negative, that is, not a target item, the bottom, unilluminated panel had to be pressed for the rcward. On trials with correct responses, probe images were extinguished following completed delivery of the reward. Incorrect responses resulted in immediate extinction of the probe image and the sounding of a raucous air horn, some macaques also receiving a brief air puff to the snout.

To encourage animals to respond as quickly but as accurately as possible, the durations both of rewards and of punishments were inversely scaled to the reaction time for each trial. Correct short-latency responses thus produced large rewards, whereas incorrect short-latency responses produced long-duration punishments. Response latencies were measured with millisecond resolution from the instant of probe onset to the first press of the top or bottom panel.

For this experiment, a partially "fixed-set" version of Sternberg's task was cmploycd. The number of probe trials associated with each target list depended on the memory load. In a pseudorandom manner, each element of the target list was probed twice, once through each eye, along with an equal number of test-set unique negative probes. For example, for a test set with a memory load of four targets, there was a total of 16 probe trials, eight positive (each of the four items twice) and eight negative. Following correct responses, 2 sec ensued before the next test trial began. Incorrect responses were followed by a $5 \mathrm{sec}$ "time-out." Throughout probe testing, the computer controlled the viewing eye according to a prespecified file, constructed to assure collection of sufficient data in each experimental condition. When necessary, switching of the occluded eye occurred at the beginning of the intertrial interval, prior to self-initiation of the next trial. This gave the animals time to "adjust" before a new probe was actually presented. After completion of a test block, a $10 \mathrm{sec}$ interval ensucd beforc presentation of the next target list began.

Stimulus presentations and data acquisition were controlled by a DEC PDP1 1-23 computer interfaced with State Systems, Inc. Colbourn modules. Each experimental session was composed of 6-10 separate test blocks of various memory loads. Within a given session, images that served as targets in one test block were not presented as probes in other blocks. On the other hand, half of the images that served as negative probes for one test block served again as negative probes in other test blocks. This was done in an effort to encourage the classification of probes on the basis of the relevant target list and not upon a simple judgment of stimulus novelty. Images that were used as targets in one experimental session were inevitably used as negative probes in other sessions and vice versa. Each test session typically required $20 \mathrm{~min}$ and subjects participatcd in onc or two scssions daily (a minimum of $3 \mathrm{hr}$ separating sessions). Throughout, every effort was made to ensure the animal's comfort.

Stimuli. Target and probe images were selected from an inventory of 100 different multicolored patterns. All stimuli had lateral symmetry (Fig. 1), which ensured that left and right eye views of each image were completely comparable, a necessity for proper testing of interhemispheric abilities in split-chiasm animals (Hamilton et al., 1973). All animals were highly familiar with the task and stimulus inventory at the time of formal testing, each having worked on the task for a minimum of three months beyond the time when it achieved initial criterion performance $(>85 \%$ correct on binocular trials with a memory load of six items). The images making up each target set were continually changed, so there was no opportunity to learn specific target lists.

Data analyses. Reaction time data are casily contaminated by shortlatency fast-guess responses (Yellot, 1971), as well as by long-latency responses from trials where subjects are not concentrating. Neither of these types of responses reflects the latency of stimulus-controlled processing (the variable of interest), so it is important that an effort be made to minimize their impact on parameter estimates. Thus, a $5 \%$ symmetric trimming (which eliminated the slowest and fastest $5 \%$ of responses) was applied prior to all subsequent data analyses. Such trimming is preferable to the more common practice of eliminating values more than 3 standard deviations beyond the mean, because of the nonGaussian shape of reaction time distributions. Parameters for response latency and accuracy functions were derived for each animal via linear least-squares regressions of the relevant trimmed data on the predictor variable of memory load.

Testing strategy. The ability to control the eye that viewed each stimulus allowed examination of the issue of interhemispheric processing via comparison of two key classes of probe trials: (1) intrahemispheric trials, where the eye viewing the probe was also the eye that had viewed all members of the target set; and (2) interhemispheric trials, where the target designation had been made to the nonprobed eye and hemisphere. Previous experience indicated that animals lacking all commissural pathways became understandably frustrated if they were repeatedly punished for failing in the interhemispheric transfer of information. Active punishment on interhemispheric trials was, therefore, not used with split-brain animals for memory loads of two, four, or six items, although it was maintained during test sets with memory loads of one, in order to encourage animals to try to gain interhemispheric access.

To examine the possibility of hemispheric asymmetries, data were compared from right versus left intrahemispheric trials of test sets where all of that set's targets had been viewed by the same hemisphere. Of particular interest were the slopes of each hemisphere's functions relating reaction time and accuracy to memory load. A comparison of interhemispheric trials, where the left versus right hemisphere viewed the initial targets, allowed for evaluation of possible asymmetries in the direction of transfer of information.

The examination of bihemispheric integration required a complex form of target set in which the target information was distributed between the hemispheres. Of key interest was comparison of intrahemispheric performance under conditions where (1) each of six targets had been viewed by the same eye as that evaluating a probe (the $6 / 6$ condition), (2) the probed eye had viewed only four of the six targets (the $4 / 6$ condition), and (3) the probed eye had viewed only two of the six targets (the $2 / 6$ condition). Figure 3 provides an example of this type of test set.

If the hemispheres act as isolated and independent information processing systems, performance on the $2 / 6$ condition should be much better than that under the $6 / 6$ condition, and in fact it should not be different from that of a $2 / 2$ condition where the total memory load is two targets, both of which are viewed by the probed hemisphere. That is, loading the nonprobed hemisphere with four additional targets (the essential difference between $2 / 2$ and $2 / 6$ conditions) should be of no consequence. In contrast, if the brain always works as an integrated whole, bihemispheric division of a target set of six elements should be inconsequential. That is, performance on the $6 / 6$ condition should be equivalent to that displayed on $4 / 6$ and $2 / 6$ conditions.

A given day's test session consisted of several test blocks, each designed to address one or more of the above issues. Thus, throughout the duration of the experiment, data relevant to each of these issues were collected in an interleaved rather than blocked manner. The data reported herein were derived from more than 7200 probe trials per subject, per test period (intact, optic chiasm transected, partial commissurotomy, complete commissurotomy). A 2-4 week recovery period followed each surgical intervention, and an additional $1-2$ week retraining period preceded each new testing phase.

\section{Results}

Table 2 summarizes averaged data for the five animals (Lan-I, Walt-I, Art-AC, Spa-AC, and Buck-SP) that were tested prior to any surgical interventions. Hand use had no significant effect on the slopes of reaction time or accuracy functions, so unless otherwise stated, the data in all subsequent tables and figures represent an average across right- and left-hand test conditions. The data of Table 2 illustrate the abilities of the monkeys to respond rapidly and accurately in all test conditions. Equation parameters (intercept and slope) for each individual subject were extremely stable, with the SEM being about $1 \%$ of the mean. There was some variability in derived parameters from one animal to the next, but even here the SEM for the grand averages 


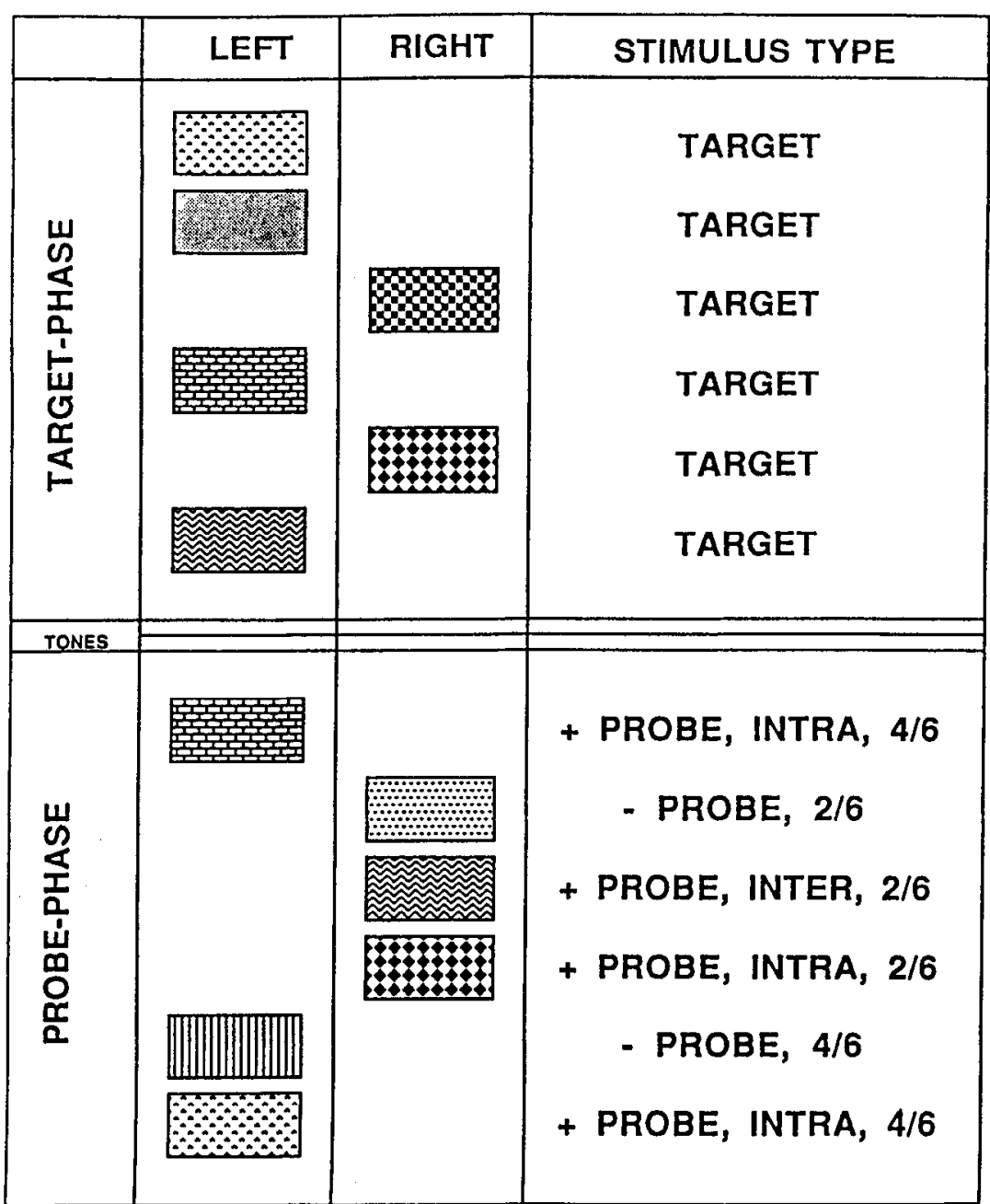

Figure 3. Example of a distributed target set. During the target phase, each of six images is presented to only one eye/hemisphere. Probe images are also presented to only one eye/hemisphere. A probe can be negative (not matching any targets), positive via an intrahemispheric route (matching a target previously viewed by the same eye/ hemisphere), or positive via an interhemispheric route (matching a target previously viewed by the contralateral eye/hemisphere). Each probe is categorized according to the memory load of the probed hemisphere, and the total memory load. For example, the first probe is + via an intrahemispheric route, the probed hemisphere having viewed four of six targets. (shown in Table 2) was typically less than $20 \%$ of the mean (e.g., for the right-right latency function for positive probes, the SEM of the grand average was $81 \mathrm{msec}$ for the intercept, and 0.8 $\mathrm{msec} /$ target for the slope). The only exception to this was the value for the intercepts of negative probe latency functions. This value was highly variable across subjects (although very stable for each individual subject), displaying a range from 410 to 620 msec. Post hoc analyses of the data suggest that this result may

Table 2. Average performance of five intact animals, all targets to same eye

\begin{tabular}{llll}
$\begin{array}{l}\text { Target-probe } \\
\text { condition }\end{array}$ & \multicolumn{2}{l}{ Latency function $(\mathrm{msec})$} & $\begin{array}{l}\text { Accuracy } \\
\text { function } \\
(\%)\end{array}$ \\
\cline { 2 - 4 } positive probes & negative probes & \\
\hline Right-right & $415+4.0 \times$ & $510+3.4 \times$ & $96.0-1.7 \times$ \\
Zeft-left & $416+5.4 \times$ & $510+4.4 \times$ & $96.0-1.6 \times$ \\
Right-left & $424+4.5 \times$ & $506+3.4 \times$ & $94.0-2.0 \times$ \\
Left-right & $422+5.3 \times$ & $509+5.9 \times$ & $93.0-2.0 \times$ \\
\hline
\end{tabular}

P.esented values are the group average $(N=5)$ of the parameters from functions aiculated for each monkey. Latency functions for each animal were based upon approximately 600 trials -150 trials at each memory load (one, two, four, six). Accuracy functions for each animal reflected 1200 trials (600 positive and 600 negative). For each group average equation, $x$ indicates the memory load where all targets had been presented to the indicated eye. For example, the average latency of Right-right positive probe trials where the memory load was six targets is given by the equation $415+(4.0 \times 6)=439 \mathrm{msec}$. have mostly reflected physical factors (the short arm reach of Lan-I and Spa-I) and not processing factors per se (see Lewine, 1989).

In all cases, the characteristic Sternberg result of latency increasing and accuracy decreasing, as a function of memory load, was observed. Increasing memory load from one to six images typically resulted in a reaction time increase of about $30 \mathrm{msec}$, and a decrease in response accuracy of 10 percentage points. Responses on negative probe trials were significantly slower than corresponding responses to positive probes, a result common in the human literature, although for humans the effect is usually not as large as that observed here. There was no evidence of species-wide left/right asymmetries. Interocular processing was generally as fast as intraocular processing, although it was slightly, but consistently, less accurate $(2-3 \%, p<0.05)$.

Three of the animals (Art-AC, Spa-AC, and Buck-SP) were tested again following transection of the optic chiasm. Even for the most difficult conditions, this loss of $>50 \%$ of the visual input to each hemisphere had essentially no effect on response accuracy (Fig. 4, top), although there was some slowing of response latency (Fig. 4, bottom). Interocular (now interhemispheric) processing remained nearly equivalent to intrahemispheric processing, and parcellating target information between the hemispheres continued to have no effect on performance.

Table 3 presents data for Buck-SP and Mer-SP at the time when the posterior, splenial $5 \mathrm{~mm}$ of the callosum was the sole 
remnant of the forebrain commissures, that is, after the anterior commissure and most of corpus callosum had been transected. Performance remained excellent, the surgery in no way exacerbating the mild interocular deficit present even for intact animals. Neither animal demonstrated significant left/right asymmetries, nor was there any significant effect of parcellating the memory load between the hemispheres (Table 4). It is noteworthy that these findings held regardless of the eye/hand combination being used. Each animal displayed an inherent speed advantage for using one hand versus the other (about $10 \mathrm{msec}$ ), but this did not interact with memory load or viewing eye; responses with an ipsilateral eye/hand combination were as accurate and rapid as those made with the contralateral combination. When given free choice of which hand to use, animals showed only a mild preference for the hand contralateral to the viewing eye.

Complete callosotomy, leaving the anterior commissure intact, had several intriguing effects on processing ability. The most dramatic of these was a peculiar attentional deficit manifested during early trials with the ipsilateral eye/hand combination. During the first few "retraining sessions" after surgery, both Art-AC and Spa-AC acted as though they were blind when called upon to use an ipsilateral eye/hand combination in the evaluation of a probe. What made this situation so curious was the additional observations that these monkeys had no difficulty in using the ipsilateral combination for retrieving a marshmallow, or for acknowledging the initial list of target images. Only when a decision as to which panel to press (upper vs lower) was called for, did the behavioral problem appear. As discussed below, this suggests a subtle attentional deficit, not a deficit in general ipsilateral eye/hand motor coordination. Interestingly, after about 1 week of being repeatedly confronted with the ipsilateral situation, both animals became as proficient with the ipsilateral as they were with the contralateral combination. The extent to which this reflects training versus a more global recovery from surgical intervention remains unclear.

With respect to interhemispheric processing, the anterior commissure was a very efficient pathway, able to support a performance level of greater than $75 \%$ correct, even when the memory load was six targets. However, the anterior commissure may be a slightly less efficient pathway than the callosum. When tested after chiasm transection, Buck-SP, Art-AC, and Spa-AC each displayed an interhemispheric deficit of only $3 \%$ relative to intrahemispheric abilities. Transection of the anterior commissure and anterior callosum (leaving only the splenium) did not aggravate the interhemispheric deficit for Buck-SP (Mer-SP also demonstrated only a $3 \%$ deficit with only splenium intact),
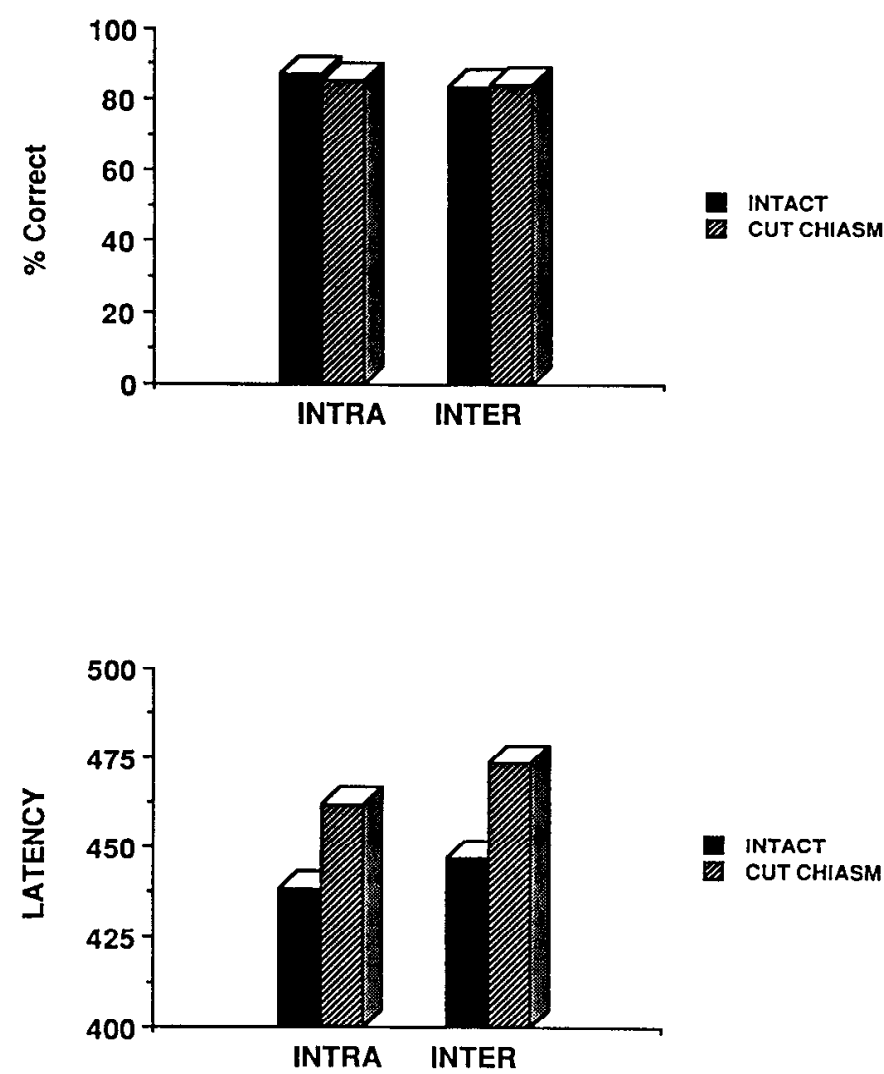

Figure 4. Top, Lack of effect of chiasm transection on response accuracy for both intra-and interhemispheric conditions $(p>0.1)$. Group averaged data $(N=3)$ are presented for the condition where the memory load was six targets, all viewed by the same eye. Each bar reflects 1800 trials total (600 per animal). Bottom, Significant effect of chiasm section on response latency $(p<0.05)$. Group averaged $(N=3)$ data for responses to positive probes are presented. On average, chiasm transection resulted in an increase in response latency of $25 \mathrm{msec}$ beyond presurgical values (range, $18-32 \mathrm{msec}$ ). There was no differential effect on intraversus interhemispheric processing.

whereas callosotomy caused a significant $(p<0.05)$ increase in this to about $6 \%$ for Art-AC and Spa-AC (Table 5).

Art-AC and Spa-AC displayed some functional asymmetries postcallosotomy. For Art-AC, responses made when the right hemisphere was probed were significantly slower (about $25 \mathrm{msec}$, $p<0.05$ ) than comparable responses with the left hemisphere. There was also an asymmetry with respect to the direction of interhemispheric transfer, probes presented to the right being responded to more slowly than those presented to the left. The

Table 3. Intra- and interhemispheric performance with the splenium intact, all targets to same eye

\begin{tabular}{lllll} 
Animal & Condition & \multicolumn{2}{l}{ Latency function $(\mathrm{msec})$} & \multicolumn{2}{l}{$\begin{array}{l}\text { Accuracy } \\
\text { function } \\
\text { (\%) }\end{array}$} \\
\cline { 3 - 4 } Buck-SP & Intra & $416+4.5 \times$ & $453+5.6 \times$ & $95.0-1.0 \times$ \\
& Inter & $427+3.6 \times$ & $455+2.6 \times$ & $91.2-0.7 \times$ \\
\multirow{2}{*}{ Mer-SP } & Intra & $550+4.5 \times$ & $673+5.5 \times$ & $93.2-1.8 \times$ \\
& Inter & $545+6.9 \times$ & $677+5.4 \times$ & $90.4-1.2 \times$
\end{tabular}

Data from right and left eye presentations have been combined. For each animal, latency equations are based upon 1200 trials per condition (intra vs. inter). Accuracy data are based upon 2400 trials per condition. The SEM for each equation parameter was less than $2 \%$ of the mean value (e.g., if the mean latency was 500 msec the SEM was less than 10 insec). The average accuracy deficit in interhemispheric processing relative to intrahemispheric processing was less than $3 \%$, even when the memory load was six targets. Latency differences were not significant. 
Table 4. Distributed target conditions, splenium intact

\begin{tabular}{|c|c|c|c|c|c|c|c|}
\hline \multirow[b]{2}{*}{ Animal } & \multirow[b]{2}{*}{$\begin{array}{l}\text { Distribution } \\
\text { (MLP/TML) }\end{array}$} & \multicolumn{2}{|l|}{+ Intra } & \multicolumn{2}{|l|}{+ Inter } & \multicolumn{2}{|l|}{ - Probe } \\
\hline & & $\begin{array}{l}\text { Latency } \\
\text { (msec) }\end{array}$ & $\begin{array}{l}\text { Accuracy } \\
(\%)\end{array}$ & $\begin{array}{l}\text { Latency } \\
\text { (msec) }\end{array}$ & $\begin{array}{l}\text { Accuracy } \\
(\%)\end{array}$ & $\begin{array}{l}\text { Latency } \\
\text { (msec) }\end{array}$ & $\begin{array}{l}\text { Accuracy } \\
(\%)\end{array}$ \\
\hline \multirow[t]{4}{*}{ Buck-SP } & $6 / 6$ & 442 & 89.1 & NA & NA & 490 & 88.1 \\
\hline & $4 / 6$ & 450 & 87.2 & 453 & 87.0 & 477 & 87.3 \\
\hline & $2 / 6$ & 452 & 90.3 & 448 & 86.9 & 488 & 87.1 \\
\hline & $0 / 6$ & NA & NA & 445 & 85.2 & 475 & 85.6 \\
\hline \multirow[t]{4}{*}{ Mer-SP } & $6 / 6$ & 574 & 88.2 & $\mathrm{NA}$ & NA & 709 & 88.0 \\
\hline & $4 / 6$ & 590 & 87.3 & 578 & 87.4 & 701 & 87.7 \\
\hline & $2 / 6$ & 575 & 87.0 & 582 & 85.0 & 715 & 87.5 \\
\hline & $0 / 6$ & NA & NA & 590 & 86.2 & 698 & 85.6 \\
\hline
\end{tabular}

Each distributed condition is specified by the memory load of the probed hemisphere (MLP) and the total memory load (TML). Right and left eye trials have been combined. In each case, the TML was six images, with the memory load of the probed hemisphere varying from zero to six images. The $0 / 6$ distribution does not apply (NA) for positive $(+)$ intrahemispheric probes where, by definition, the matching target was viewed by the probed hemisphere. By similar logic, the $6 / 6$ distribution does not apply for positive $(+)$ interhemispheric probes. Each value is based on 300 trials. The SEM for each value was approximately $4 \%$ of the mean. There was no linear trend in either latency or accuracy related to the distribution of the target list $(p>0.1)$.

magnitude of these asymmetries did not interact with memory load. That is, they were manifest in the intercepts of reaction time functions, not the slopes. This indicates differences at processing stages other than the mnemonic search stage. Spa-AC did not display asymmetries for intrahemispheric conditions, but did show an asymmetry related to the direction of interhemispheric transfer. When the left hemisphere was queried about targets that had been viewed by the right, performance was almost $10 \%$ worse than in the reverse situation. The asymmetry was not modified by increasing memory load. The extent to which these asymmetries were inherent versus induced by extracallosal damage incurred during surgery remains uncertain, but the latter possibility seems more likely, and is consistent with structural damage confirmed by subsequent histology (see Table 7).

One of the most significant differences in the performance of animals with the splcnium versus antcrior commissure intact was revealed by parcellating the target list between the hemispheres. Recall that for Buck-SP and Mer-SP the interhemispheric distribution of the target set was of no consequence for either the latency or accuracy of response. The same was generally true for Art-AC and Spa-AC, except that the distribution of the target list had a very significant impact on the latency of response to positive intrahemispheric probes (Table 6). When required to recognize that a monocular probe matched a target image initially viewed by the same hemisphere, response latency reflected the memory load of that hemisphere only. Yet, if the probe was negative, or positive via an interhemispheric route, the target distribution did not matter.

Surgical transection of all remaining forebrain commissural fibers had a dramatic effect on the processing abilities of each of the four relevant animals (Art-AC, Spa-AC, Buck-SP, and Mer-SP). Initially, split-brain animals displayed difficulties in the use of the ipsilateral eye/hand combination. These difficulties were similar to those displayed by $\Lambda \mathrm{rt}-\Lambda \mathrm{C}$ and Spa-AC immediately after callosotomy. The deficit appeared to be one of an inability to appropriately guide attentional mechanisms, not a fundamental problem in ipsilateral motor control per se. As was found after callosotomy, each animal managed to overcome this problem after 2-15 training sessions, the ipsilateral eye/hand combination becoming as proficient as the contralatcral combination.

As shown in Figure 5, completed transection of the forebrain commissures had less than a $10 \%$ effect on intrahemispheric abilities, while it completely disrupted interhemispheric abilities, even when the memory load was only one item. It should be noted that animals were not hesitant on interhemispheric trials. Rather, they rapidly and "confidently" indicated that a posilive interhemispheric probe was a negative probe-a technically incorrect response-yet the appropriate response for a

Table 5. Intra- and interhemispheric performance with the anterior commissure intact, all targets to same eye

\begin{tabular}{lllll} 
& & \multicolumn{2}{l}{ Latency function $(\mathrm{msec})$} & \multicolumn{2}{c}{$\begin{array}{l}\text { Accuracy } \\
\text { function } \\
(\%)\end{array}$} \\
\cline { 3 - 5 } Animal & Condition & positive probes & negative probes & $96.2-1.4 \times$ \\
\hline Art-AC & Intra & $452+7.2 \times$ & $497+7.3 \times$ & $90.5-1.7 \times$ \\
& Inter & $457+6.6 \times$ & $491+5.1 \times$ & $85.4-1.1 \times$ \\
Spa-AC & Intra & $461+4.5 \times$ & $673+5.5 \times$ & $79.8-0.9 \times$
\end{tabular}

Data from right and left eye presentations have been combined. For each animal, latency equations are based upon 1200 trials per condition (intra vs. inter). Accuracy data are based upon 2400 trials per condition. The SEM for each equation parameter was less than $2 \%$ of the mean value. The average deficit in accuracy for interhemispheric processing relative to intrahemispheric processing was about $6 \%$-significantly more than the precallosotomy deficit of $3 \%(p<0.05)$. 
Table 6. Distributed target conditions, anterior commissure intact

\begin{tabular}{|c|c|c|c|c|c|c|c|}
\hline \multirow[b]{2}{*}{ Animal } & \multirow[b]{2}{*}{$\begin{array}{l}\text { Distribution } \\
\text { (MLP/TML) }\end{array}$} & \multicolumn{2}{|l|}{+ Intra } & \multicolumn{2}{|l|}{+ Inter } & \multicolumn{2}{|l|}{ - Probe } \\
\hline & & $\begin{array}{l}\text { Latency } \\
\text { (msec) }\end{array}$ & $\begin{array}{l}\text { Accuracy } \\
(\%)\end{array}$ & $\begin{array}{l}\text { Latency } \\
(\mathrm{msec})\end{array}$ & $\begin{array}{l}\text { Accuracy } \\
(\%)\end{array}$ & $\begin{array}{l}\text { Latency } \\
\text { (msec) }\end{array}$ & $\begin{array}{l}\text { Accuracy } \\
(\%)\end{array}$ \\
\hline \multirow[t]{4}{*}{ Art-AC } & $6 / 6$ & 497 & 86.8 & $\mathrm{NA}$ & NA & 540 & 87.1 \\
\hline & $4 / 6$ & 483 & 87.0 & 490 & 79.1 & 528 & 86.1 \\
\hline & $2 / 6$ & 466 & 88.1 & 488 & 84.1 & 532 & 87.0 \\
\hline & $0 / 6$ & NA & NA & 500 & 77.2 & 524 & 85.6 \\
\hline \multirow[t]{4}{*}{ Spa-AC } & $6 / 6$ & 506 & 77.8 & NA & $\mathrm{NA}$ & 660 & 78.2 \\
\hline & $4 / 6$ & 494 & 77.5 & 495 & 74.0 & 672 & 76.7 \\
\hline & $2 / 6$ & 481 & 81.0 & 489 & 74.1 & 658 & 77.1 \\
\hline & $0 / 6$ & NA & NA & 497 & 72.0 & 633 & 71.3 \\
\hline
\end{tabular}

Each distributed condition is specificd by the memory load of the probed hemisphere (MLP) and the total memory load (TML). Right and left eye trials have been combined. Each value is based on 300 trials. The SEM for each value was approximately $4 \%$ of the mean. In general, parcellating the target list had little effect on performance. However, for positive $(+)$ intrahemispheric probes there was a significant linear relationship between response latency and the memory load of the probed hemisphere $(p<0.01)$. When the memory load of the probed hemisphere was only two of six items $(2 / 6)$, performance was $25+\mathrm{msec}$ faster than when the probed hemisphere had viewed all six targets $(6 / 6)$. There was no linear trend for response accuracy $(p>0.1)$.

hemisphere with no knowledge of the mnemonic database of its disconnected partner. Following commissurotomy, each animal displayed marked hemispheric asymmetries in the intercepts of reaction time and accuracy functions. For example, on average, Mer-SP was $60 \mathrm{msec}$ slower and 10\% less accurate on right than left trials. Art-AC displayed similar asymmetries, but the direction of asymmetry was the opposite for Buck-SP, who was $30 \mathrm{msec}$ faster and $7 \%$ more accurate on right versus left trials. The performance of Spa-AC was rather poor in all conditions, with left hemisphere responses being somewhat less accurate than right hemisphere responses. The right-left asymmetries that each animal displayed in the intercepts of response latency and accuracy functions can perhaps be explained, post hoc, on the basis of unilateral extracallosal damage that each animal suffered during surgery (Table 7). Histology revealed that Mer-SP had incurred herniation of right medial aspects of the sensorimotor cortex, the right fornix was absent, the right septum was greatly thinned, and the right ventral cingulate gyrus was missing throughout its length. Art-AC's histology revealed damage to the right fornix, septum, and habenula, whereas BuckSP had incurred minor damage to the left fornix, left posterior cingulate cortex, and left retrosplenial area. For Spa-AC, the right fornix was absent and the left nucleus basalis partly damaged.

For both hemispheres of each animal, response accuracy de. creased, and response latency increased as a nearly linear function of memory load. This suggests that mnemonic retrieval was achieved by qualitatively similar mechanisms for the two hemispheres. However, each macaque displayed minor asymmetric:s in the magnitude of the slopes of response latency and accuracy as a function of memory load. In contrast to those asymmetrie: in the intercepts (which were inconsistent from animal to anima! and readily traceable to unilateral extracallosal damage), slope asymmetries were consistent across the monkeys. Table 8 summarizes this effect, showing the extent to which intrahemispheric performance changed as memory load was increased from one to six items in right versus left hemispheres. The data indicate that response latency increased and response accuracy decrease? more rapidly (as a function of memory load) for loading and probing of the right versus left hemispheres. That is, in eact case, the retrieval process per se was significantly more efficier: for the left hemisphere $(p<0.05)$. Right-left differences we
Figure 5. Effects of completed commissurotomy on response accuracy. Group averaged data derived from animals Art-AC, Spa-AC, Buck-SP, and Mer-SP are presented from testing in the split-brain postcommissurotomy state and from testing immediately prior to the last surgical intervention (precommissurotomy, splenium intact for Buck-SP and Mer-SP, anterior commissure intact for Art-AC and Spa-AC). The data are from trials where the memory load was only one target (600 trials per animal). Even under this minimally taxing condition, animals consistently made negative responses to monocular probes matching targets previously viewed through only the opposite eye.

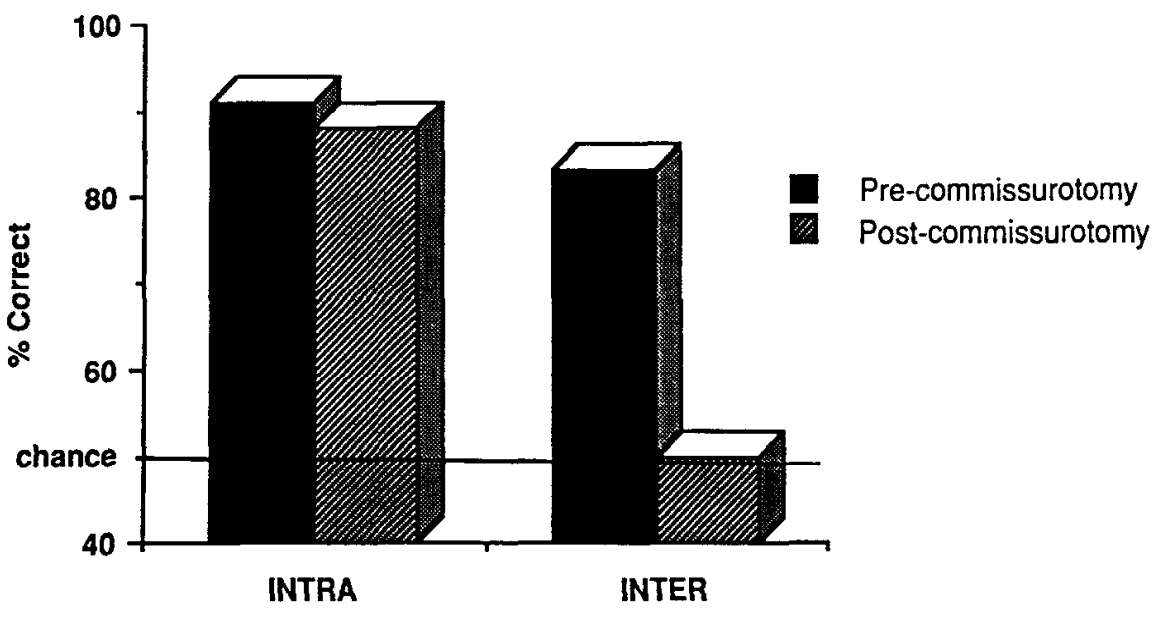


Table 7. Histological findings and functional asymmetries

\begin{tabular}{|c|c|c|c|c|c|}
\hline \multirow[b]{3}{*}{ Animal } & \multirow[b]{3}{*}{ Damaged regions } & \multicolumn{4}{|c|}{ Poorer performing hemisphere } \\
\hline & & \multicolumn{2}{|c|}{ Intercepts } & \multicolumn{2}{|c|}{ Slope } \\
\hline & & $\overline{\mathrm{RT}}$ & $\%$ & $\overline{\mathrm{RT} T}$ & $\%$ \\
\hline Art-AC & $\mathrm{R}$ fornix, $\mathrm{R}$ septum, $\mathrm{R}$ habenula & $\mathbf{R}$ & $\mathbf{R}$ & $\mathrm{R}$ & $\mathrm{R}$ \\
\hline Buck-SP & $\mathrm{L}$ fornix, $\mathrm{L}$ cingulate, $\mathrm{L}$ retrosplenial areas & L & $\mathrm{L}$ & $\mathrm{R}$ & $\mathbf{R}$ \\
\hline Mer-SP & $\mathrm{R}$ fornix, $\mathrm{R}$ septum, $\mathrm{R}$ cingulate, $\mathrm{R} \mathrm{s} / \mathrm{m}^{a}$ & $\mathbf{R}$ & $\mathbf{R}$ & $\mathrm{R}$ & $\mathrm{K}$ \\
\hline Spa-AC & $\mathrm{R}$ fornix, $\mathrm{L}$ nucleus basalis & $\mathbf{R}$ & $\mathrm{L}$ & $\mathrm{R}$ & $\mathbf{R}$ \\
\hline
\end{tabular}

Functional asymmetries in split-brain animals - relationship with extracallosal damage. Extracallosal damage was incurred by each animal. RT refers to reaction time functions whereas \% refers to accuracy functions. The intercept provides a measure of baseline performance (related to nonmnemonic factors per se), whereas the slope provides a measure of the rate at which performance declines (accuracy decreases, latency increases) as the memory load is increased.

${ }^{a}$ Minor damage to sensorimotor cortex.

admittedly small, but the consistency from animal to animal suggests that they may reflect a true species-wide asymmetry in the efficiency of mnemonic retrieval processes.

Complete commissurotomy isolated the mnemonic databases held by each hemisphere, so it was expected that the intrahemispheric performance of each hemisphere would be influenced only by its own memory load. This was indeed the case with respect to response latency, reaction time on both positive and negative trials being a function of the memory load of the probed hemisphere only. Figure 6 illustrates this point, the loading of the nonprobed hemisphere having little consequence on response latency. Figure 7 demonstrates that dividing a total memory load of six targets between the hemispheres resulted in a decrease in reaction time. Overall, when the probed hemisphere had viewed only two of six target images, performance was faster than when that hemisphere had viewed six targets (the $6 / 6$ condition). In fact, performance was as rapid as when there were only two targets total (Table 9). With respect to accuracy, however, the situation was quite different. Figure 8 shows that loading the nonprobed hemisphere had a significant impact on the accuracy of performance of the probed hemisphere, while Figure 9 shows that distributing a memory load of six targets had minimal impact on overall response accuracy of either hemisphere! That is, despite the fact that each hemisphere had no access to the mnemonic contents of the other, the act of remembering targets by one hemisphere disrupted mnemonic retrieval by the other. Table 10 summarizes the effective memory load for distributed conditions. Effective memory load was determined by first calculating the latency and accuracy functions for data blocks where the memory loads were one and six targets, all of which had been presented to the probed hemisphere. The equation was then set equal to the average latency or accuracy value for each distributed condition $(4 / 6,2 / 6)$, and solved for the memory load value. With respect to response latency, the effective memory load reflected that of the probed hemisphere only, whereas the effective memory load with respect to accuracy of response never dropped below five targets, even when the probed hemisphere had viewed only two of six targets.

\section{Discussion}

Hemispheric asymmetries. Each split-brain animal tested here displayed some left/right asymmetries, but interpretation of this result is complicated by unilateral damage to one or more extracallosal structures (Table 7). Unilateral fornix involvement was most common, but it is uncertain at which procedure this damage occurred. The largest asymmetries for split-brain animals were found in the intercepts of response latency and accuracy functions and, in all instances, whichever side of the brain had suffered the most extracallosal damage displayed the poorer performance. Asymmetric intercepts imply asymmetries in attentive, encoding, decision, and/or response mechanisms for the two hemispheres. The available data do not support the hypothesis that unilateral fornix damage disrupts the mnemonic search process per se, because the side of fornix damage was not well correlated with asymmetries in the slopes of reaction time and accuracy functions. Fornix lesions probably exert their effect in memory tasks through a reduction in the quality of information initially stored, or through a disruption of the process by which the level of activation for engrams is evaluated (see below).

Beyond the asymmetries in the intercepts of response latency and accuracy functions, there were also asymmetries in the slopes

Table 8. Change in performance as memory load was increased from one to six targets

\begin{tabular}{|c|c|c|c|c|c|c|}
\hline \multirow[b]{2}{*}{ Animal } & \multicolumn{2}{|c|}{$\begin{array}{l}\text { + Probe latency } \\
(\mathrm{msec})\end{array}$} & \multicolumn{2}{|c|}{$\begin{array}{l}\text { - Probe latency } \\
\text { (msec) }\end{array}$} & \multicolumn{2}{|c|}{$\begin{array}{l}\text { Overall accuracy } \\
(\%)\end{array}$} \\
\hline & $\mathrm{R}$ & $\mathrm{L}$ & $\mathrm{R}$ & $\mathrm{L}$ & $\mathrm{R}$ & $\mathrm{L}$ \\
\hline Art-AC & +45 & +34 & +42 & +20 & $-16 \%$ & $-07 \%$ \\
\hline Buck-SP & +28 & +16 & +18 & +13 & $-13 \%$ & $-10 \%$ \\
\hline Mer-SP & +36 & +22 & +24 & +14 & $-13 \%$ & $-05 \%$ \\
\hline Spa-AC & +34 & +21 & +40 & +24 & $-19 \%$ & $-12 \%$ \\
\hline
\end{tabular}

Data are from intrahemispheric trials only. For each animal, latency increased and accuracy decreased more for loading of the right versus left hemisphere. That is, the right hemisphere was consistently less capable of maintaining performance in the face of increasing mnemonic demands. Each value is based on 900 trials. Righv/left differences are significant for each animal and for the group as a whole $(p<0.05)$. 

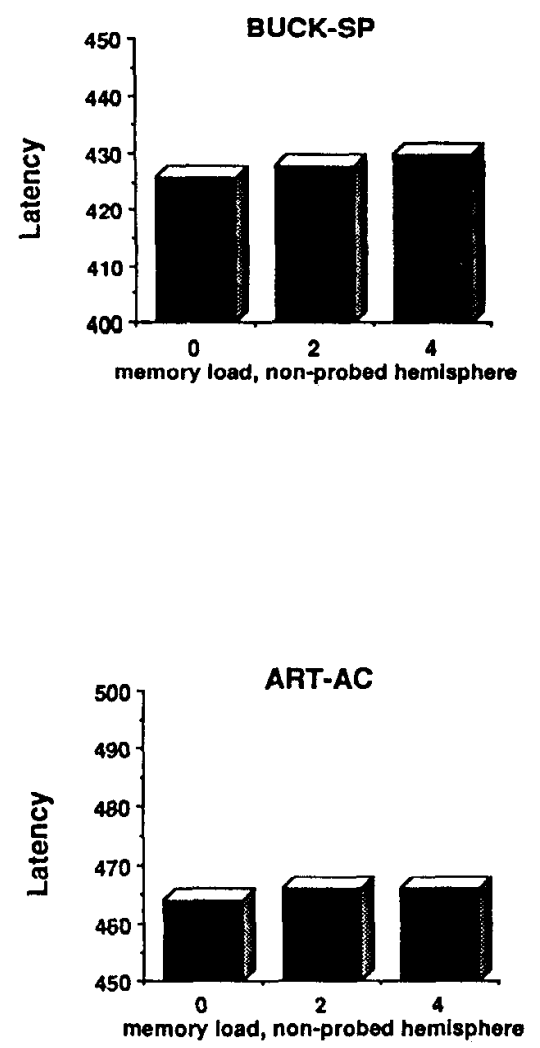
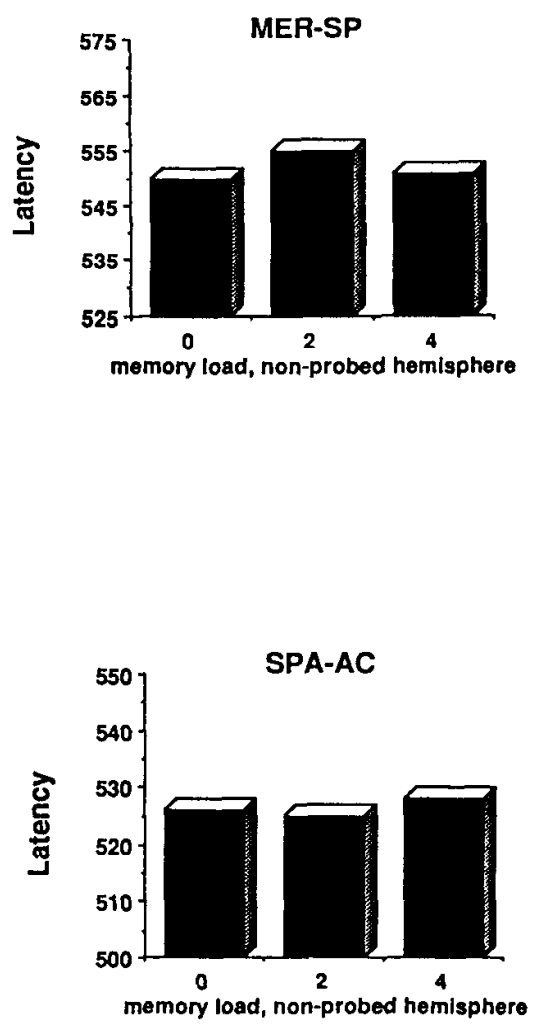

Figure 6. Loading the nonprobed hemisphere failed to perturb response latency in split-brain animals. Average reaction time on positive probe trials where the probed hemisphere had viewed two targets is shown $(N=600$ for each condition). The data illustrate that loading the nonprobed hemisphere with four additional targets caused no significant $(p>0.1)$ change in latency. Similar findings were observed on negative probe trials. sphere was less encumbered than the right by increasing mnemonic load. This is noteworthy in extending previous data on macaques (Hamilton and Vermeire, 1991), which revealed asymmetries in perception and in the learning of rules and habits. The present data suggest the existence of additional asymmetries in the retrieval of data from working event memory. The monkey result is concordant with data from visual half-
Figure 7. In split-brain animals, when the total memory load was six targets, distributing the targets between the hemispheres resulted in significantly faster reaction times. Shown for each split-brain animal is the average $(N=$ 600 ) latency on positive probe trials where the probed hemisphere had viewed six of six, four of six, or two of six targets (i.e., the total number of targets was the same in each case). In each instance, the effective memory load reflected the memory load of the probed hemisphere $(p<0.01)$, rather than the total memory load (six in all cases). Similar data were observed on negative probe trials.
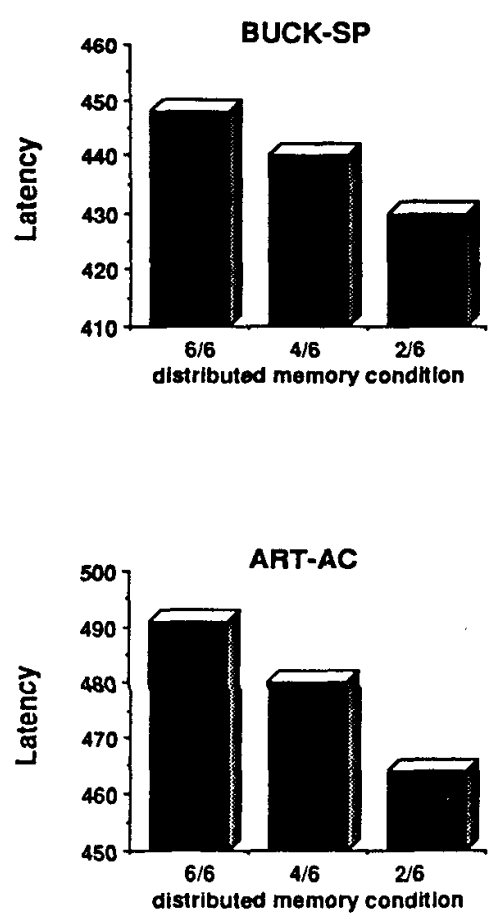
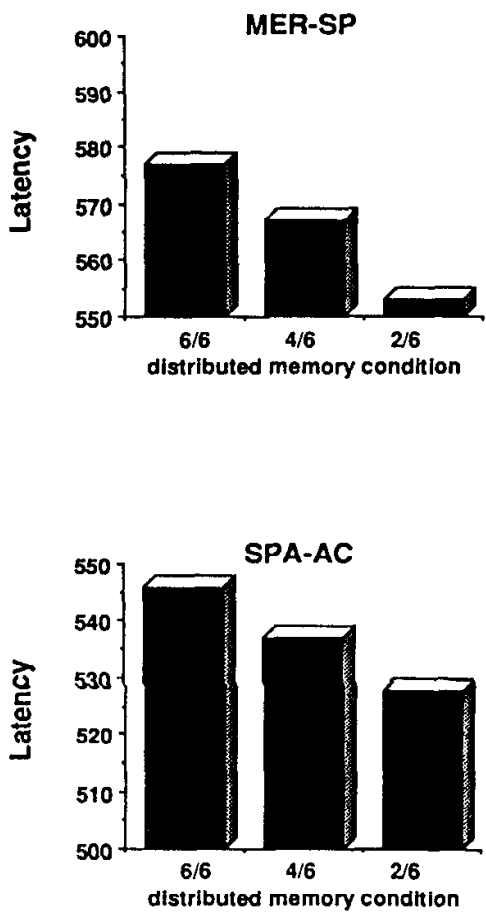


\begin{tabular}{|c|c|c|c|c|c|c|c|c|}
\hline \multirow{2}{*}{$\begin{array}{l}\text { Condi- } \\
\text { tion } \\
\text { (MLP/ } \\
\text { TML) }\end{array}$} & \multicolumn{2}{|c|}{ Art-AC } & \multicolumn{2}{|c|}{ Buck-SP } & \multicolumn{2}{|c|}{ Mer-SP } & \multicolumn{2}{|c|}{ Spa-AC } \\
\hline & + & - & + & - & + & - & + & - \\
\hline $2 / 2$ & 466 & 493 & 426 & 511 & 550 & 711 & 526 & 660 \\
\hline $2 / 6$ & 464 & 492 & 430 & 514 & 553 & 709 & 528 & 659 \\
\hline $6 / 6$ & 491 & 516 & 448 & 526 & 577 & 727 & 546 & 685 \\
\hline
\end{tabular}

Each distributed condition is specified by the memory load of the probed hemisphere (MLP) and the total memory load (TML). Right and left eye trials have been combined. Each value is based on 600 trials. The SEM for each value was approximately $2 \%$ of the mean. For each animal, response latency on the $2 / 6$ condition resembled that of the $2 / 2$ condition more closely than it resembled the latency of the $6 / 6$ condition, with a strong $(p<0.01)$ linear trend in the regression of latency on the predictor variable of MLP. That is, the memory load of the probed hemisphere (MLP), rather than the total memory load (TML), was the key factor in determining response latency.

field studies in neurologically intact human subjects. For example, Madden and Nebes (1980) used a version of the Sternberg task in which target digits were presented at fixation, and probes were subsequently presented tachistoscopically in the right or left visual half-field. Response latency functions were steeper for left versus right visual half-field evaluations, an observation indicative of more efficient mnemonic processing by the left hemisphere. Similar observations have been made using letters (Moscovitch, 1972; Hellige, 1980) and pictures (Klatzky and Atkinson, 1971) as stimuli.

Interhemispheric mechanisms. Even prior to any surgical intervention, subjects demonstrated a small (2-3\%) but significant $(p<0.05)$ deficit in interocular as compared to intraocular processing. The import of this is not clear, but it suggests that, either perceptually or mnemonically, data acquired via one eye do not become wholly congruent with that from the other. Hence, there is a slight mismatch between the perception of a stimulus viewed through one eye and a memory trace of the same image established via the other eye.

Transection of the optic chiasm, which eliminates $>50 \%$ of the visual input to each hemisphere, had little effect on the accuracy of visual mnemonic performance. Indeed, following this procedure the three relevant animals (Art-AC, Spa-AC, and Buck-SP) displayed no difficulty whatever in resuming their performance, even for the interocular situation, beginning, in one instance, as carly as $12 \mathrm{~d}$ after the surgery. Chiasm transection did result in a general slowing of reaction time across all conditions, a result suggestive of a nonspecific effect on visual arousal.

Further restriction of commissural pathways to only the splenium of the corpus callosum also had essentially no effect on performance, whereas restriction to only the anterior commissure induced a mild deficit in interhemispheric abilities without inducing a concomitant deficit in intrahemispheric processing. Nevertheless, the data clearly demonstrate that the anterior commissure is very efficient at supporting interhemispheric transfer, at least for macaques, performance levels exceeding $70 \%$ even when the memory load was six targets. These data confirm previous observations (Doty et al., 1988b; Ringo et al., 1991) that, in addition to their ability to support the interhemispheric exchange of mnemonic information relevant to rules and procedures, the anterior commissure and splenium of macaques are each capable of accurate interhemispheric exchange of information on specific visual events. Examination of the response latency data from animals with one or more commis-
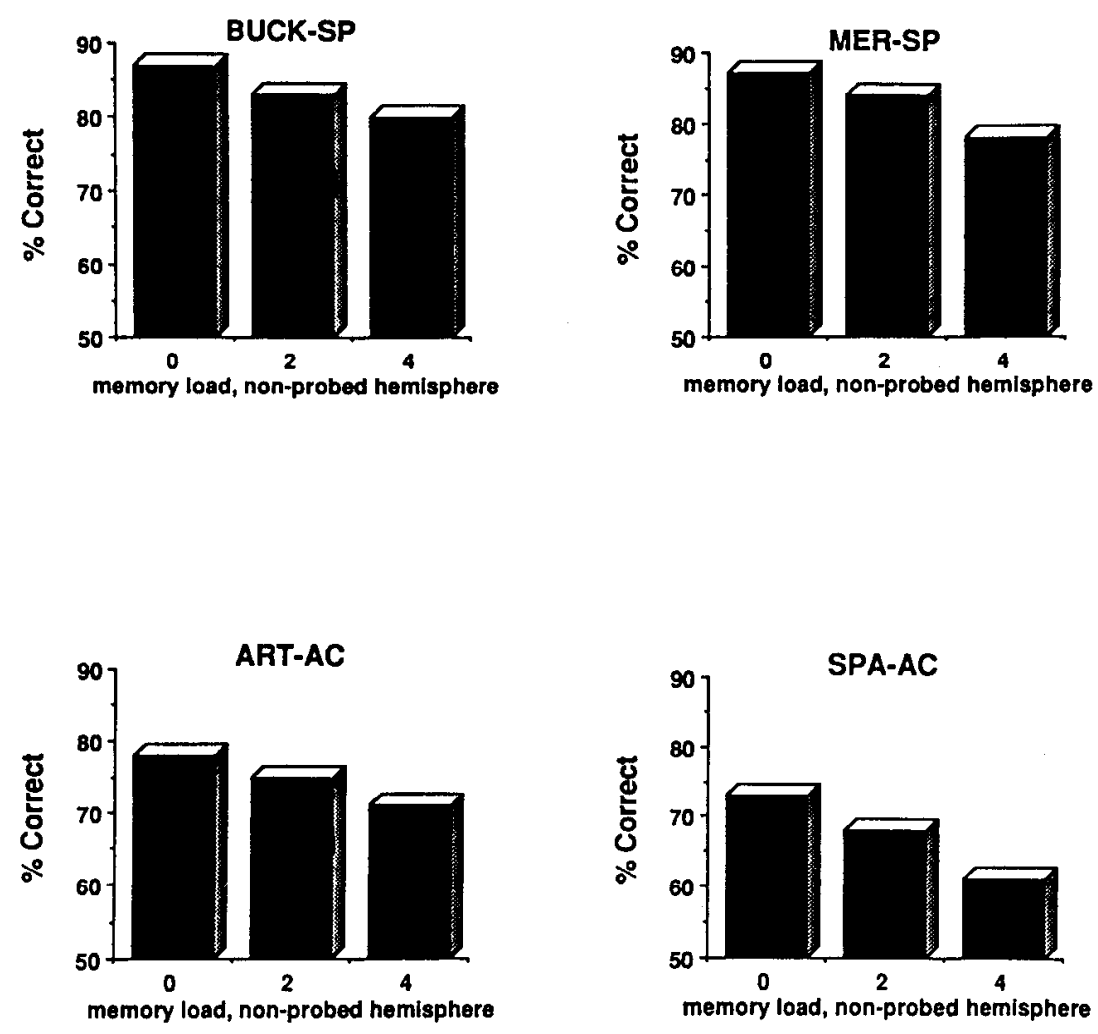

Figure 8. Loading the nonprobed hemisphere caused a perturbation of response accuracy in split-brain animals. Average percentage correct performance on trials where the probed hemisphere had viewed two targets is shown ( $N=1200$ for each condition). The data illustrate that loading the nonprobed hemisphere with four additional targets causcd a significant disruption in performance $(6-12 \%, p<0.01)$. 

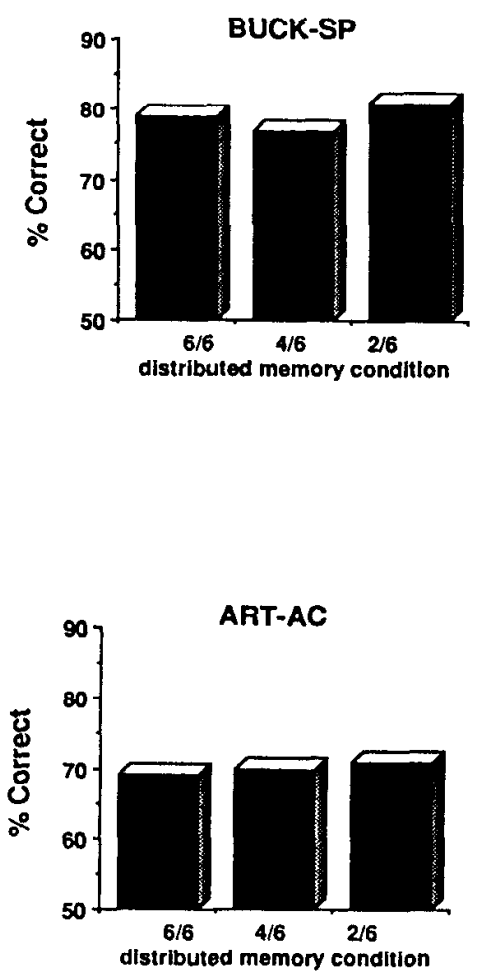
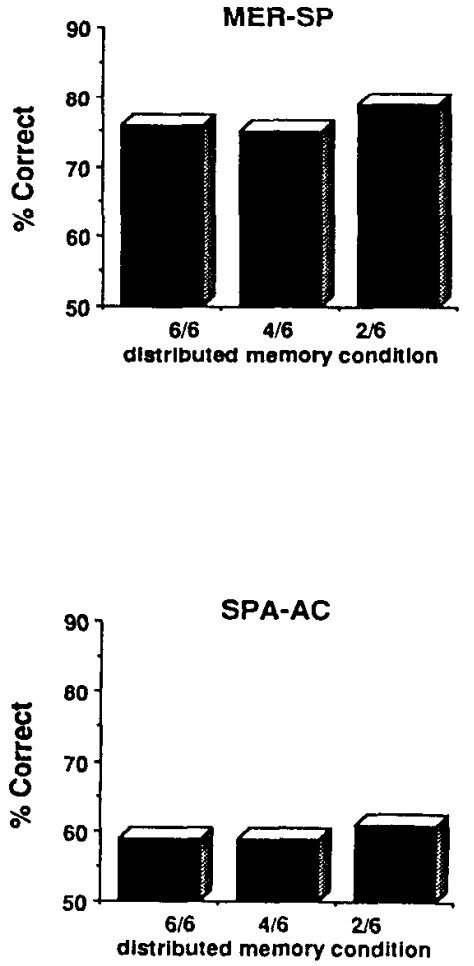

Figure 9. In split-brain animals, when the total memory load was six targets, distributing the targets between the hemispheres did not have an effect upon response accuracy. For each split-brain animal, the average $(N=1200)$ percentage correct performance on trials where the probed hemisphere had viewed six of six, four of six, or two of six targets is shown. There was a mild $(2-3 \%)$ tendency for responses in the $2 / 6$ condition to be more accurate than responses in the $6 / 6$ condition, but the effective memory load was closer to five than to two targets.

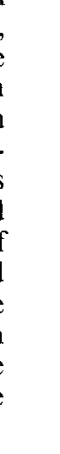

sural pathways intact revealed that there were no significant differences in the timing of intra- versus interhemispheric responses. This suggests that unilateral target presentations produce a bilateral mnemonic store, as clearly evidenced as well by Ringo's (1994) data using electrical disruption to manipulate engram formation and readout. Had monocular target presentations yielded only a unilateral trace in the hemisphere receiving direct target information, the evaluation of interhemispheric positive probes should have been slower than that for intrahemispheric probes. Evoked potential studies in humans suggest that some intcrhemispheric transfer occurs in as little as $10 \mathrm{msec}$ (Lines et al., 1984; Rugg et al., 1984; Marzi et al., 1991), although interhemispheric transmission times for some commissural fibers must be in excess of $100 \mathrm{msec}$ (Swadlow et al., 1979). The failure to observe any evidence of a processing delay on interhemispheric trials therefore suggests that the probed hemisphere of splenial and $\mathrm{AC}$ animals had immediate and direct access to target information at the time the probe was presented. (Given the number of presentations tested here, a delay of as littlc as $5 \mathrm{msec}$ should have been evident.)

Present evidence holds that the consistently excellent ability of the anterior commissure to support interhemispheric visual processes in monkeys may not extend to humans. In human cases of callosal agenesis, it is clear that the anterior commissure affords some degree of visual interhemispheric communication, but in patients with callosotomy, the ability of the anterior commissure to sustain visual transfer varies greatly between patients (Rissc et al., 1978; McKeever et al., 1981). To some extent this probably reflects an extreme variability in the size of the anterior commissure across human subjects (Demeter et al., 1988). It should be noted that human subjects have yet to be tested on mnemonic tasks comparable to those used with monkeys, most of the human work requiring a comparison of stimuli presented simultaneously in the two visual half-fields-

\begin{tabular}{|c|c|c|c|c|c|c|c|c|c|c|c|c|}
\hline \multirow{2}{*}{$\begin{array}{l}\text { Condi- } \\
\text { tion } \\
\text { (MLP/ } \\
\text { TML) }\end{array}$} & \multicolumn{3}{|c|}{ Art-AC } & \multicolumn{3}{|c|}{ Buck-SP } & \multicolumn{3}{|c|}{ Mer-SP } & \multicolumn{3}{|c|}{ Spa-AC } \\
\hline & + & - & $\%$ & + & - & $\%$ & + & - & $\%$ & + & - & $\%$ \\
\hline $6 / 6$ & 6.0 & 6.0 & 6.0 & 6.0 & 6.0 & 6.0 & 6.0 & 6.0 & 6.0 & 6.0 & 6.0 & 6.0 \\
\hline $4 / 6$ & 4.1 & 4.2 & 5.6 & 3.9 & 4.1 & 6.2 & 4.0 & 3.9 & 6.1 & 4.4 & 4.5 & 5.9 \\
\hline $2 / 6$ & 2.5 & 2.0 & 5.1 & 2.3 & 2.1 & 5.0 & 2.2 & 1.9 & 5.2 & 2.4 & 2.0 & 5.1 \\
\hline
\end{tabular}

Effective memory load is determined by substituting the measured value of performance (latency or accuracy) into the equation for the linear regression of performance on the predictor variable MLP (memory load for the probed hemisphere), and solving for the memory load. For example, if the latency function is $400+5 \times$ (where $\times$ is the memory load), and empirical latency in the $4 / 6$ condition is $420 \mathrm{msec}$, then the effective memory load is found by solving the equation $420=400+5 \times$. Data are given for the latency of positive $(+)$ and negative $(-)$ probe trials, and also for overall accuracy of response $(\%)$. Where effective memory load for specifying response latency closely follows MLP values, the effective memory load is relatively constant with respect to response accuracy. 
a task that taps attentional and perceptual factors rather than mnemonic mechanisms.

When relying only upon the anterior commissure, animals initially acted as though they were partly blind when called upon to use ipsilateral eye-hand combinations on probe trials. The monkeys clearly knew when a probe had been presented, but they tended to flail their arms at the response panels in an uncoordinated manner. This behavior was in marked contrast to the smooth, controlled movements the animals made on interleaved probe trials involving contralateral eye-hand combinations. It is well documented that split-brain human and monkey subjects display difficulties when required to guide discrete finger movements via the ipsilateral hemisphere (e.g., Sperry et al., 1969; Brinkman and Kuypers, 1973), but such difficultics werc not anticipated for the rather gross arm movements required here.

Similar observations, however, had been made on split-brain animals in Downer's laboratory (Downer, 1959; Lund et al., 1970). Downer and his colleagues found split-brain monkeys to be quite capable of retrieving objects with the ipsilateral eyehand combination, but these same animals were extremely clumsy when initially called upon to use this ipsilatcral combination during visual discrimination tasks. Trevarthen (1962, 1965) has reported related data that split-brain macaques performing concurrent bihemispheric discriminations often fail to assimilate the input to one eye, this unilateral neglect being associated with the side ipsilateral to the responding hand. In fact, for split-brain subjects, it seems that "spontaneous" initiation of a movement with one hand can draw altention completely away from the ipsilateral hemisphere. In a fascinating incident related by Trevarthen (1974), split-brain subject N.G. reported that a rather large object she had been viewing in the right visual field completely vanished coincident with the initiation of a movement of her left hand.

Together, these observations and others (see Guiard, 1979) suggest that the forebrain commissures normally play an important role in the switching of attention from one hemisphere to the other. When the commissural pathways are transected, the hemisphere ipsilateral to the responding hand may have difficulty gaining access to the resources it needs for discriminant evaluation of incoming probe information. The data suggest that the callosum is normally the dominant player in controlling the lateral directing of attention, but the anterior commissure can come to mediate this in the absence of the callosum.

Bihemispheric integration. Provided that the splenium of the corpus callosum was intact, the interhemispheric distribution of the target set was of little consequence. However, for animals with only the anterior commissure, response latency for positive intrahemispheric probe trials reflected only the memory load of the probed hemisphere. It was as though it were possible for the relevant animals (Art-AC and Spa-AC) to scan selectively the target list of the probed hemisphere. If a within-hemisphere probe-target match was found, a response was immediately generated, but if there were no match, then, and only then, would the target list from the other hemisphere be accessed (the total time on both negative probe trials and interhemispheric positive trials reflecting the entire memory load).

This explanation is intuitively appealing, especially if only unilateral engrams are generated by monocular target presentations: first scan intrahemispherically, then engage transcallosal mechanisms, if necessary. However, if it were the case that transcommissural access were being accomplished during the retrieval process, there should have been evidence, at the time of probe, of a time delay for the interhemispheric transfer of data. The fact that reaction times on probe trials were the same for intra- and interhemispheric conditions implies that monocularly presented target information was directly available to each hemisphere at the time of probe testing. Indeed, this situation of bilateral mnemonic activation seems to be the rule in animals with only the anterior commissure intact (see Doty et al., 1973; Ringo et al., 1991; Ringo, 1994). Given this, the data from anterior commissure animals imply the existence of multiple memory stores within each hemisphere, one for intrahemispherically established targets and a separate one for interhemispherically established targets. The intrahemispheric store is scanned first, and only if no match is found is the interhemispheric store scanned. On the surface, this hypothesis of separate intra- and interhemispheric stores within each hemisphere seems cumbersome and ad hoc, but, from a neural point of view, this is no more strange than hypothesizing separate mnemonic stores for auditory and visual information - different sensory pathways provide input to different mnemonic stores.

Following completed commissurotomy, each hemisphere was unable to access the mnemonic database of its disconnected partner. The observation that response latency reflected only the memory load of the probed hemisphere was therefore an expected result. The same argument should apply with respect to the accuracy of responses, yet this clearly was not the case, the mnemonic loading of one hemisphere having a significant impact on the accuracy of processing by the other (Figs. 8, 9; Tables 9,10 ). There was a tendency for distributing the target list to have a mild unburdening result, but the effect was small; for example, where the probed hemisphere had viewed only two of six targets, accuracy was equivalent to that of about five intrahemispheric targets rather than the full load of six.

In evaluating these results, it is important to consider factors other than the mnemonic loading of the nonprobed hemisphere that could account for the near equivalence of accuracy (Fig. 9) on trials where the probed hemisphere had viewed two of six versus six of six targets (the $2 / 6$ versus $6 / 6$ condition). Of particular note is the possibility that response accuracy (but not latency) is selectively affected by the delay between target and probe presentations. Extensive data sets from delayed matchand nonmatch-to-sample experiments clearly indicate the importance of delay as a mnemonic factor (e.g., Mishkin and Appenzeller, 1987), and in the present experiments the same amount of time was required for the presentation of distributed and nondistributed lists of six targets. However, if delay were an overriding factor, serial position effects within the target and/ or probe list should have been evident. That is, positive probes presented early in the probe list, and matching targets presented late in the target list, should have been evaluated more efficiently than positive probes presented at the end of the probe phase and matching early items in the target list (because the time delay between target and matching probe presentations is shorter in the former vs latter case). For all animals, this type of serial position effect was absent in all data sets. Related observations have been made using continuous recognition tasks with both human (J. D. Lewine, unpublished observations) and monkey (Doty et al., 1985) subjects, where it has been found that the number of intervening items that occur between first and second presentations of a particular item is a much more potent mnemonic factor than the intervening time delay.

The observation that each disconnected hemisphere was un- 
aware of the details of targets held by the other hemisphere implies that decreases in response accuracy (which are associated with increasing memory load) do not reflect direct "interference" between memory representations. Overall, the data indicate that the working memory database of each hemisphere is separate, but mnemonic processing by the hemispheres is not independent - a result implying that disconnected hemispheres compete for allocation of processing resources drawn from a centrally allocated, limited pool.

A similar view has been put forth by Holtzman and Gazzaniga (1982), who tested a human split-brain subject on a related itemrecognition task. In their experiment, the subject (who had a transected corpus callosum, but intact antcrior commissure) was tested under two target display conditions. In the "redundant" condition, each hemisphere had to memorize the same three items. In the "mixed" condition, one hemisphere was presented with three items for memorization while the other was given only a single target (presented three times). When the hemisphere loaded with three different targets was tested in each condition, it was found that performance in the mixed condition was better than that in the redundant case. That is, it mattered whether the nonprobed hemisphere had viewed one (mixed) versus three (redundant) targets. Other studies (e.g., Teng and Sperry, 1974) also report indirect task interference between the hemispheres of human split-brain subjects. Interestingly, even for neurologically intact subjects, interhemispheric interference is typically less than intrahemispheric interference. That is, when subjects must concurrently perform two tasks (i.e., in dual task studies), the decrement that the addition of the secondary task causes in performance of the primary task is typically less when the tasks are directed toward different hemispheres than when they are both directed to the same hemisphere (e.g., Kinsbourne and Cook, 1971; Kreuter et al., 1972; Kinsbourne, 1973, 1974; Liederman et al., 1985; Hellige, 1987; Hellige et al., 1988). This observation is fully consistent with the latency data from the present experiment. It is also consistent with the accuracy data where the interhemispheric distribution of the target list (a situation parallel to the interhemispheric directing of two concurrent tasks) was associated with a slight increase in accuracy. (Recall that the effective memory load for determining accuracy in the $2 / 6$ condition was five rather than six items.)

The picture thus emerges that there is only a partial insulation of mnemonic processes within each hemisphere even in the absence of the forebrain commissures. The present data, like those of Holtzman and Gazzaniga (1982), suggest that the hemispheres must each utilize mnemonic resources held in common. This implies that subcortical mechanisms play a more important and specific role in mnemonic processing than is traditionally recognized, and it suggests that the intact brainstem is the most likely source of this effect.

Although the nature of shared mnemonic resources is obscure, it is nevertheless tempting to spcculate that they rclate to active maintenance of information within working memory. The following model is proposed. Whenever a stimulus is presented, a new activated engram is formed (if the stimulus is truly novel) or the level of activation for its previously established mnemonic representation is incremented (in the present experiment all stimuli were highly familiar to the animals). Normally, the level of mnemonic activation decays rapidly, so the maintenance of a particular target inventory for several probe trials therefore requires repetitive internal reactivation of target engrams until such time as the target information is no longer needed (e.g., when a new target set is designated). It is proposed that the unified brainstem mediates this incremental reactivation process for both hemispheres. To the extent that only one engram can be reactivated at a time, the more engrams that must be reactivated, the longer the time between successive reactivations for each particular engram. As a result, the average level of activation across engrams decreases as a function of the memory load.

To account for the present data, the process of discriminating between positive and negative probes is speculated to involve two steps. The first consists of identification of (searching for) that engram best related to the incoming probe information. When a probe is presented, it automatically causes an increase in the mnemonic activation level for its associated mnemonic representation. However, the more engrams within the probed hemisphere that were already being maintained as active by the brainstem (i.e., target engrams), the more difficult it is to identify which engram of the probed hemisphere was specifically activated by the probe, because there is a signal-to-noise problem. As a result, the time required for identification of the proberelevant engram increases as a function of memory load of the probed hemisphere.

The second step in the probe discrimination process is an evaluation of the absolute level of mnemonic activation for the probe-relevant engram. If the probe-relevant engram had in fact been a target engram, its postprobe level of activation reflects the sum of its preprobe level of activation (imparted to it by the brainstem reactivation process) and the natural increment in activity imparted by presentation of a matching probe. If during the response decision process the strength of the proberelevant engram is found to be above an internally set criterion, the engram is presumed to have been one of the original targets, and a positive response is generated. If the strength is below criterion, the engram is presumed not to have been a target, and a negative response is generated. As the preprobe strength of target engrams reflects the entire memory load, so too does postprobe strength. The more targets, independent of their bihemispheric distribution, the lower the absolute strength of activation for a probe-relevant target engram. Given that there is undoubtedly noise in the recognition process, the greater the memory load, the more likely it is that the strength of a proberelevant target engram will fall below the positive response criterion. That is, the more targets, the higher the error rate, independent of the bihemispheric distribution of targets.

The present experiments reveal a disassociation of reaction time and accuracy measures in the Sternberg task that clearly urges a reevaluation of various theories of mnemonic retrieval presently current in cognitive psychology, since the majority of available models (e.g., Ratcliff, 1978; Pike, 1984; Hockley and Murdock, 1987) presume that accuracy and reaction time are alternative measures of a single underlying mnemonic factor (e.g., probe-relatedness in Ratcliff's diffusion model).

\section{References}

Austin G, Hayward W, Rouhe S (1974) A note on the problem of conscious man and cerebral disconnection by hemispherectomy. In: Hemispheric disconnection and cerebral function (Kinsboume $M$, Smith WL, eds), pp 95-114. Springfield, IL: Thomas.

Brinkman J, Kuypers HGJM (1973) Cerebral control of contralateral and ipsilateral arm, hand and finger movements in the split-brain rhesus monkey. Brain 96:653-674.

Doty RW, Negrao N, Yamaga K (1973) The unilateral engram. Acta Neurobiol Exp (Warz) 33:711-728. 
Doty RW, Lewine JD, Ringo JL (1985) Mnemonic interaction between and within cerebral hemispheres in macaques. In: Neural mechanisms of conditioning (Alkon DL, Woody CD, eds), pp 223-231. New York: Plenum.

Doty RW, Ringo JL, Lewine JD (1988a) Humanlike characteristics of visual mnemonic system in macaques. In: Cellular mechanisms of conditioning and behavioral plasticity (Woody CD, Alkon DL, McGaugh JL, eds), pp 303-312. New York: Plenum.

Doty RW, Ringo JL, Lewine JD (1988b) Forebrain commissures and visual memory: a new approach. Behav Brain Res 29:267-280.

Downer JL (1959) Changes in visually guided behaviour following mid-sagittal division of optic chiasma and corpus callosum in monkeys (Macaca mulatta). Brain 82:251-259.

Gazzaniga MS, Young ED (1967) Effects of commissurotomy on the processing of increasing visual information. Exp Brain Res 3:368371.

Glassman RB, Negrao N, Doty RW (1969) A safe and reliable method for temporary restraint of monkeys. Physiol Behav 4:431-432.

Gott PS (1973) Language after dominant hemispherectomy. J Neurol Neurosurg Psychiat 36:1082-1088.

Gower FC (1990) The long-term retention of events in monkey memory. Behav Brain Res 38:191-198.

Griffith H, Davidson M (1966) Long-term changes in intellect and behaviour after hemispherectomy. J Neurol Neurosurg Psychiatry 29: 571-576.

Guiard Y (1979) Report of a severe accuracy deficit in the split-brain monkey performing a between-hand choice-RT task: evidence for a unilateral functioning hypothesis. In: Structure and function of cerebral commissures (Russell IS, van Hoff MW, Berlucchi G, eds), pp 365-370. London: Macmillan.

Hamilton CR, Vermeire BA (1991) Functional lateralization in monkeys. In: Cerebral laterality: theory and research (Kitterle FL, ed), pp 19-34. Hillsdale, NJ: Erlbaum.

Hamilton CR, Tieman SR, Brody BA (1973) Interhemispheric comparison of mirror image stimuli by chiasm sectioned monkeys. Brain Res 58:415-425.

Hellige JB (1980) Effects of perceptual quality and visual field of probe stimulus presentation on memory search for letters. J Exp Psychol [Human Percept] 6:639-651.

Hellige JB (1987) Interhemispheric interactions: models, paradigms and recent findings. In: Duality and unity of the brain (Ottoson D, ed), pp 454-495. New York: Plenum.

Hellige JB, Jonsson JE, Michimata C (1988) Processing from LVF, RVF and BILATERAL presentations: examination of metacontrol and interhemispheric interaction. Brain Cognit 7:39-53.

Hockley WE, Murdock BB Jr (1987) A decision model for accuracy and response latency in recognition memory. Psychol Rev 94:341358 .

Holtzman JD, Gazzaniga MS (1982) Dual task interactions due exclusively to limits in processing resources. Science 218:1325-1327.

Holtzman JD, Gazzaniga MS (1985) Enhanced dual task performance following corpus commissurotomy in humans. Neuropsychologia 23: 315-321.

Kinsbourne M (1973) The control of attention by interaction between the cerebral hemispheres. In: Attention and performance (Kornblum $\mathrm{S}$, ed), pp 239-256. New York: Academic.

Kinsbourne M (1974) Mechanisms of hemispheric interaction in man. In: Hemispheric disconnection and cerebral function (Kinsbourne $M$, Smith WL, eds), pp 260-285. Springfield, IL: Thomas.

Kinsbourne M, Cook J (1971) Generalized and lateralized effects of concurrent verbalization on a unimanual skill. Q J Exp Psychol 23: 341-345.

Klatzky RL. Atkinson RC (1971) Specialization of the cerebral hemispheres in scanning for information in short-term memory. Percept Psychophys 12:379-384.

Kreuter C, Kinsbourne M, Trevarthen C (1972) Are deconnected cerebral hemispheres independent channels? A preliminary study of the effect of unilateral loading on bilateral finger tapping. Neuropsychologia 10:453-461.

Lewine JD (1989) The temporal dynamics of event memory: a stage analysis of mnemonic processing by man and macaque. J Cognit Neurosci 1:356-371.

Lewine JD, Doty RW, Provencal S, Astur R (1987) Monkey beats man in efficiency of mnemonic retrieval. Soc Neurosci Abstr 13:206.

Liederman J, Merola J, Martinez S (1985) Interhemispheric collab- oration in response to simultaneous bilateral input. Neuropsychologia 23:673-683.

Lines CR, Rugg MD, Milner AD (1984) The effect of stimulus intensity on visual evoked potential estimates of interhemispheric transmission time. Exp Brain Res 57:89-98.

Luck S, Hillyard S, Mangun G, Gazzaniga M (1989) Independent hemispheric attentional systems mediate visual search in split-brain patients. Nature 342:543-545.

Lund JS, Downer JLC, Lumley JSP (1970) Visual control of movement in split-brain monkeys. Cortex 6:323-346.

Madden DJ, Nebes RD (1980) Hemispheric differences in memory search. Neuropsychologia 18:665-673.

Marzi CA, Bisiacchi P, Nicoletti R (1991) Is interhemispheric transfer of visuomotor information asymmetric? Evidence from a meta-analysis. Neuropsychologia 29:1163-1177.

McKeever WF, Sullivan KJ, Ferguson SM, Rayport M (1981) Typical cerebral hemisphere disconnection deficits following corpus callosum section despite sparing of anterior commissure. Neuropsychologia 19: 745-755.

Mishkin M, Appenzeller T (1987) The anatomy of memory. Sci Am 256:80-89.

Moscovitch M (1972) A choice reaction time study assessing the verbal behavior of the minor hemisphere in normal, adult humans. J Comp Physiol Psychol 80:66-74.

Ogden MA (1989) Visuospatial and other "right-hemispheric" functions after long recovery periods in left-hemispherectomized subjects. Neuropsychologia 27:765-776.

Patterson K, Vargha-Khadem F, Polkey CE (1989) Reading with one hemisphere. Brain 112:39-63.

Pike $R$ (1984) Comparison of convolution and matrix distributed memory systems for associative recall and recognition. Psychol Rev 91:281-294.

Ratcliff R (1978) A theory of memory retrieval. Psychol Rev 85:59108.

Ringo JL (1994) The medial temporal lobe in encoding, retention, retrieval and interhemispheric transfer of visual memory in primates. Exp Brain Res, in press.

Ringo JL, Doty RW (1985) A macaque remembers pictures briefly viewed six months earlier. Behav Brain Res 18:289-294.

Ringo JL, Lewine JD, Doty RW (1986) Comparable performance by man and macaque on memory for pictures. Neuropsychologia 24: 711-717.

Ringo JL, Doty RW, Demeter S (1991) Bi-versus monohemispheric performance in split-brain and partially split-brain macaques. Exp Brain Res 86:1-8.

Risse GL, LeDoux J, Springcr SP, Wilson DH, Gazzaniga MS (1978) The anterior commissure in man: functional variation in a multisensory system. Neuropsychologia 16:23-31.

Rugg MD, Lines CR, Milner AD (1984) Visual evoked potentials to lateralized visual stimuli and the measurement of interhemispheric transmission time. Neuropsychologia 22:215-225.

Sands SF, Wright AA (1982) Monkey and human pictorial memory scanning. Science 216:1333-1334.

Schepelmann F, Prall G, Fellmann A, Recker W, Ressing H (1976) Klinisches Bild, Verhalten der motorischen Aktivitat, elektroenzephalographische, neuropsychologische und linguistische Befunde bei einem Fall von linkseitiger Hemispherektomie. Fortschr Neurol Psychiatr 44:381-432.

Smith A (1974) Dominant and non dominant hemispherectomy. In: Hemispheric disconnection and cerebral function (Kinsbourne $M$, Smith WL, eds), pp 5-33. Springfield, IL: Thomas.

Sperry RW, Gazzaniga MS, Bogen JE (1969) Interhemispheric relationships: the neocortical commissures; syndromes of hemisphere disconnection. In: Handbook of clinical neurology, Vol 4 (Vinken PJ, Bruyn GW, eds), pp 273-290. Amsterdam: Elsevier.

Sperry RW, Zaidel E, Zaidel D (1979) Self-recognition and social awareness in the deconnected minor hemisphere. Neuropsychologia 17:153-166.

Sternberg S (1966) High-speed scanning in human memory. Science 153:652-654.

Sternberg S (1969) Memory-scanning: metal processes revealed by reaction-time experiments. Am Sci 57:421-457.

Sternberg S (1975) Memory scanning: new findings and current controversies. Q J Exp Psychol 27:1-32. 
Swadlow HA, Geschwind N, Waxman SG (1979) Commissural transmission time in humans. Science 204:530-531.

Teng EL, Sperry RW (1974) Interhemispheric rivalry during simultaneous bilateral task presentation in commissurotomized patients. Cortex 10:111-120.

Trevarthen C (1962) Double visual learning in split-brain monkeys. Science 136:258-259.

Trevarthen C (1965) Functional interactions between the cerebral hemispheres of the split-brain monkey. In: Ciba Foundation Study Group, No 20, Functions of the corpus callosum (Ettlinger EG, ed), pp 24-46. Boston: Little Brown.
Trevarthen C (1972) Specialized lesions: the split-brain technique. In: Methods in psychobiology (Myers RD, ed), pp 251-284. London: Academic.

Trevarthen C (1974) Functional relations of disconnected hemispheres with the brain stem, and with each other: monkey and man. In: Hemispheric disconnection and cerebral function (Kinsbourne $M$, Smith WL, eds), pp 187-207. Springfield, IL: Thomas.

Yellot J Jr (1971) Corrections for fast guessing and the speed-accuracy tradeoff in choice reaction time. J Math Psychol 8:159-199. 